Supporting Information

\title{
Thrombospondin-1 Mimetic Agonist Peptides Induce Selective Death in Tumor Cells: Design, Synthesis and Structure-Activity Relationship Studies
}

\author{
Thomas Denèfle ${ }^{1,2,3}$, Héloise Boullet ${ }^{1,2}$, Linda Herbi ${ }^{4,5,6}$, Clara Newton ${ }^{1,2,}$ \\ ${ }^{3}$, Ana-Carolina Martinez-Torres ${ }^{4,5,6}$, Alexandre Guez ${ }^{1,2}$, Elodie Pramil ${ }^{1,}$ \\ 2,4,5,6, Claire Quiney ${ }^{4,5,6}$, Marilyne Pourcelot ${ }^{1,2,3}$, Mikail D. Levasseur ${ }^{1,2,3}$, \\ Eva Lardé ${ }^{1,2,3}$, Roba Moumné ${ }^{1,2}$, François-Xavier Ogi ${ }^{8}$, Pascal Grondin ${ }^{9}$, \\ Hélène Merle-Beral ${ }^{4,5,7}$, Olivier Lequin ${ }^{1,2}$, Santos A. Susin ${ }^{4,5,6}$ and Philippe \\ Karoyan ${ }^{1,2,3 *}$
}

${ }^{1}$ Sorbonne Universités, UPMC Univ Paris 06, Ecole Normale Supérieure, CNRS, Laboratoire des Biomolécules, Paris, France.

${ }^{2}$ Département de Chimie, Ecole Normale Supérieure, PSL Research University, UPMC Univ Paris 06, CNRS, Laboratoire des Biomolécules, Paris, France.

${ }^{3}$ UPMC Univ Paris 06, Laboratoire des BioMolécules, site GSK, 25-27 avenue du Québec 91140 les Ulis, France.

${ }^{4}$ Cell Death and Drug Resistance in Lymphoproliferative Disorders Team, Centre de Recherche des Cordeliers, INSERM UMRS 1138, Paris, France.

${ }^{5}$ Sorbonne Universités, UPMC Univ Paris 06, UMRS 1138, Paris, France.

${ }^{6}$ Université Paris Descartes, Sorbonne Paris Cité, UMRS 1138, Paris, France.

${ }^{7}$ AP-HP, GH Pitié-Salpêtrière, Service d'Hématologie Biologique, Paris, France.

${ }^{8}$ NanoTemper Technologies GmbH, Floessergasse 4, 81369 Munich, Germany.

${ }^{9}$ GSK, 25 avenue du Québec 91140 les Ulis, France.

* Corresponding author. E-mail: philippe.karoyan@upmc.fr. Phone: +3344274469

\section{CONTENTS OF SI}

1) Peptides characterization

2) CD spectra

3) NMR tables

4) Binding affinity measurements by Biolayer Interferometry (BI) and Microscale Thermophoresis (MST)

5) Cancer cell lines used in this manuscript

6) Molecular formula string (CSV) 
1) Peptides characterization

\begin{tabular}{|c|c|c|c|}
\hline Peptide & $\mathrm{Mw}\left(\mathrm{g} \cdot \mathrm{mol}^{-1}\right)$ & $m / z$ (ESI) & $t_{R}(\min )$ \\
\hline 4N1 & 1128.4 & $\begin{array}{l}1128.7[\mathrm{M}+\mathrm{H}]^{+} \\
564.9[\mathrm{M}+2 \mathrm{H}]^{2+} \\
377.1[\mathrm{M}+3 \mathrm{H}]^{3+}\end{array}$ & 1.99 \\
\hline 4N1K & 1384.8 & $\begin{array}{l}1385.8[\mathrm{M}+\mathrm{H}]^{+} \\
693.2[\mathrm{M}+2 \mathrm{H}]^{2+} \\
462.6[\mathrm{M}+3 \mathrm{H}]^{3+} \\
347.2[\mathrm{M}+4 \mathrm{H}]^{4+}\end{array}$ & 1.52 \\
\hline 4NGG & 1300.6 & $\begin{array}{l}651.3[\mathrm{M}+2 \mathrm{H}]^{2+} \\
434.6[\mathrm{M}+3 \mathrm{H}]^{3+} \\
326.3[\mathrm{M}+4 \mathrm{H}]^{4+}\end{array}$ & 1.29 \\
\hline 1 & 1169.5 & $\begin{array}{l}1169.7[\mathrm{M}+\mathrm{H}]^{+} \\
585.3[\mathrm{M}+\mathrm{H}]^{2+}\end{array}$ & 2.26 \\
\hline 2 & 1425.8 & $\begin{array}{l}713.8[\mathrm{M}+2 \mathrm{H}]^{2+} \\
416.2[\mathrm{M}+3 \mathrm{H}]^{3+} \\
357.4[\mathrm{M}+4 \mathrm{H}]^{4+}\end{array}$ & 1.69 \\
\hline 3 & 1156.5 & $\begin{array}{c}1156.8[\mathrm{M}+\mathrm{H}]^{+} \\
578.1[\mathrm{M}+2 \mathrm{H}]^{2+} \\
386.5[\mathrm{M}+3 \mathrm{H}]^{3+}\end{array}$ & 1.91 \\
\hline 4 & 1384.8 & $\begin{array}{l}693.3[\mathrm{M}+2 \mathrm{H}]^{2+} \\
462.5[\mathrm{M}+3 \mathrm{H}]^{3+} \\
347.2[\mathrm{M}+4 \mathrm{H}]^{4+}\end{array}$ & 1.54 \\
\hline M/Nle & 1366.7 & $\begin{array}{l}1367.8[\mathrm{M}+\mathrm{H}]^{+} \\
684.2[\mathrm{M}+2 \mathrm{H}]^{2+} \\
456.5[\mathrm{M}+3 \mathrm{H}]^{3+}\end{array}$ & 1.71 \\
\hline R2A & 1299.7 & $\begin{array}{l}1300.8[\mathrm{M}+\mathrm{H}]^{+} \\
650.7[\mathrm{M}+2 \mathrm{H}]^{2+} \\
434.2[\mathrm{M}+3 \mathrm{H}]^{3+}\end{array}$ & 1.76 \\
\hline F3A & 1308.7 & $\begin{array}{l}655.2[\mathrm{M}+2 \mathrm{H}]^{2+} \\
437.2[\mathrm{M}+3 \mathrm{H}]^{3+} \\
328.1[\mathrm{M}+4 \mathrm{H}]^{4+}\end{array}$ & 1.34 \\
\hline Y4A & 1292.7 & $\begin{array}{l}647.2[\mathrm{M}+2 \mathrm{H}]^{2+} \\
431.8[\mathrm{M}+3 \mathrm{H}]^{3+} \\
324.1[\mathrm{M}+4 \mathrm{H}]^{4+}\end{array}$ & 1.47 \\
\hline V5A & 1356.7 & $\begin{array}{l}679.2[\mathrm{M}+2 \mathrm{H}]^{2+} \\
453.2[\mathrm{M}+3 \mathrm{H}]^{3+} \\
340.1[\mathrm{M}+4 \mathrm{H}]^{4+}\end{array}$ & 1.47 \\
\hline V6A & 1356.7 & $\begin{array}{l}679.3[\mathrm{M}+2 \mathrm{H}] 2^{+} \\
453.2[\mathrm{M}+3 \mathrm{H}]^{3+} \\
340.2[\mathrm{M}+4 \mathrm{H}]^{4+}\end{array}$ & 1.49 \\
\hline M7A & 1324.6 & $\begin{array}{l}663.2[\mathrm{M}+2 \mathrm{H}]^{2+} \\
442.5[\mathrm{M}+3 \mathrm{H}]^{3+} \\
332.1[\mathrm{M}+4 \mathrm{H}]^{4+}\end{array}$ & 1.48 \\
\hline W8A & 1269.6 & $\begin{array}{l}635.6[\mathrm{M}+2 \mathrm{H}] 2^{+} \\
424.2[\mathrm{M}+3 \mathrm{H}]^{3+} \\
318.4[\mathrm{M}+4 \mathrm{H}]^{4+}\end{array}$ & 1.28 \\
\hline K9A & 1327.7 & $\begin{array}{l}1328.7[\mathrm{M}+\mathrm{H}]^{+} \\
664.7 \mathrm{M}+2 \mathrm{H}]^{2+} \\
443.5[\mathrm{M}+3 \mathrm{H}]^{3+}\end{array}$ & 1.83 \\
\hline
\end{tabular}

Table 1: Analytical data for the peptides. Retention times are indicated for LCMS method A. Masses determined by LC-MS (ESI) are also shown. 
- HPLC traces of the purified peptides:

4N1:

UV Detector: TIC

Range: $3.204 \mathrm{e}+1$

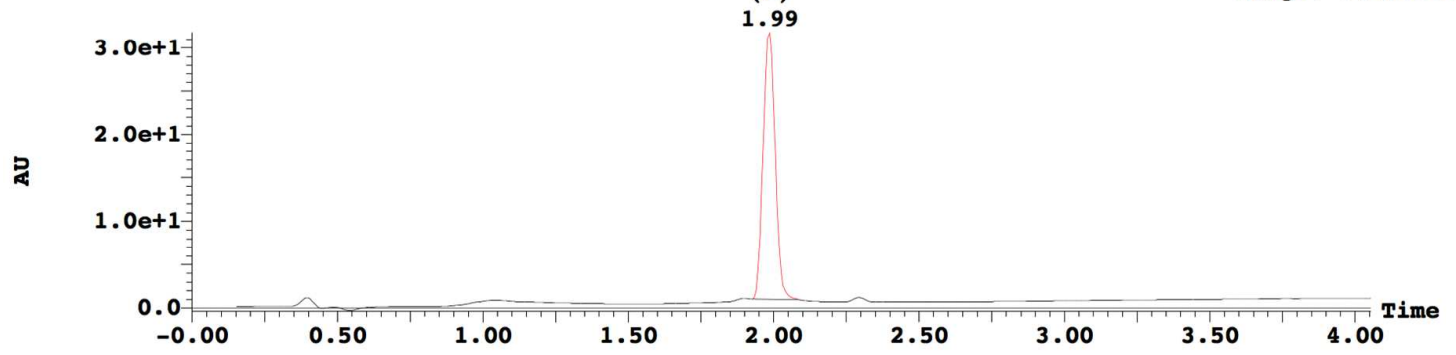

4N1K:

UV Detector: TIC
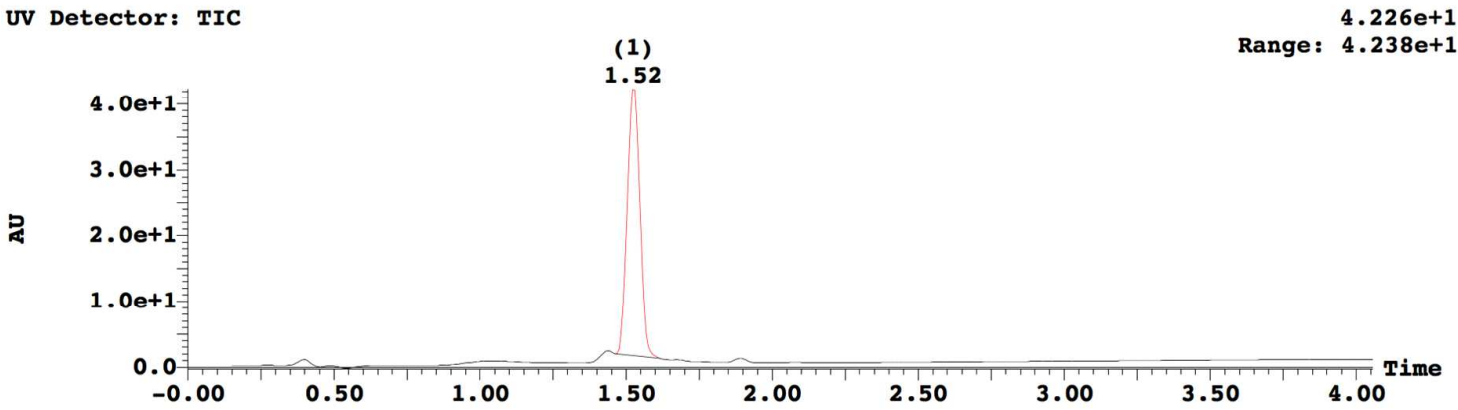

4NGG:

UV Detector: TIC

$3.518 e+1$

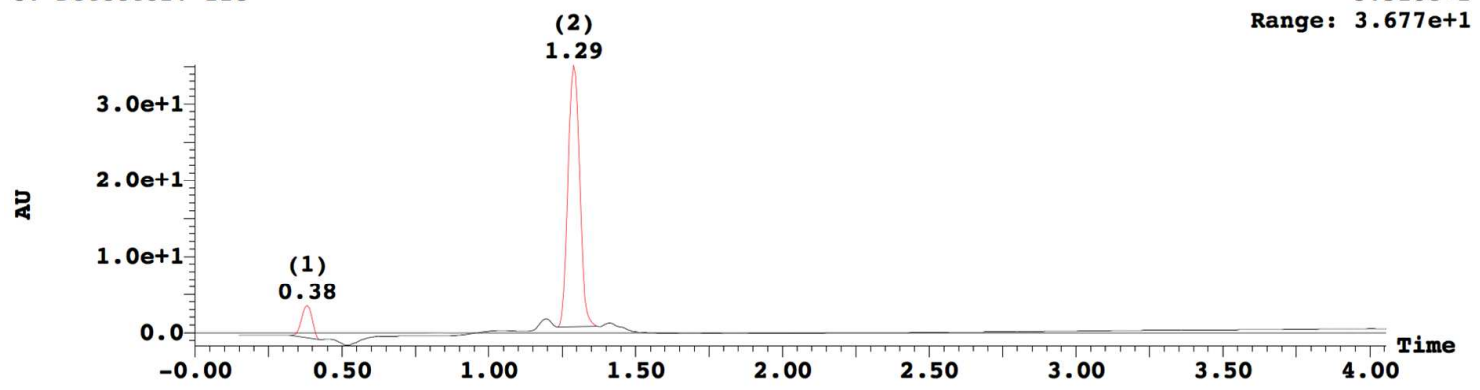

\section{Peptide 1:}

Uv Detector: TIC

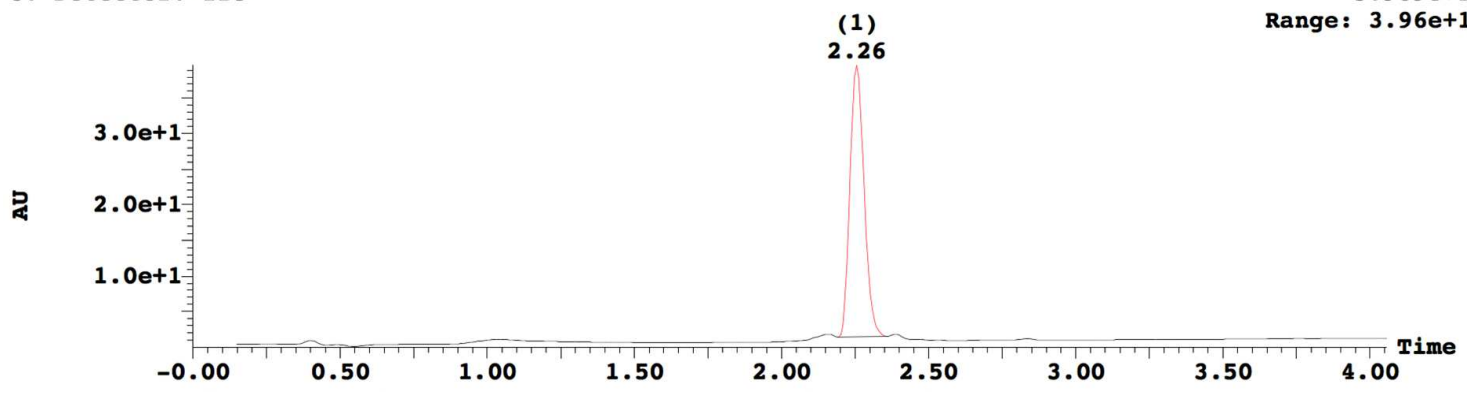




\section{Peptide 2:}

uv Detector, Tic

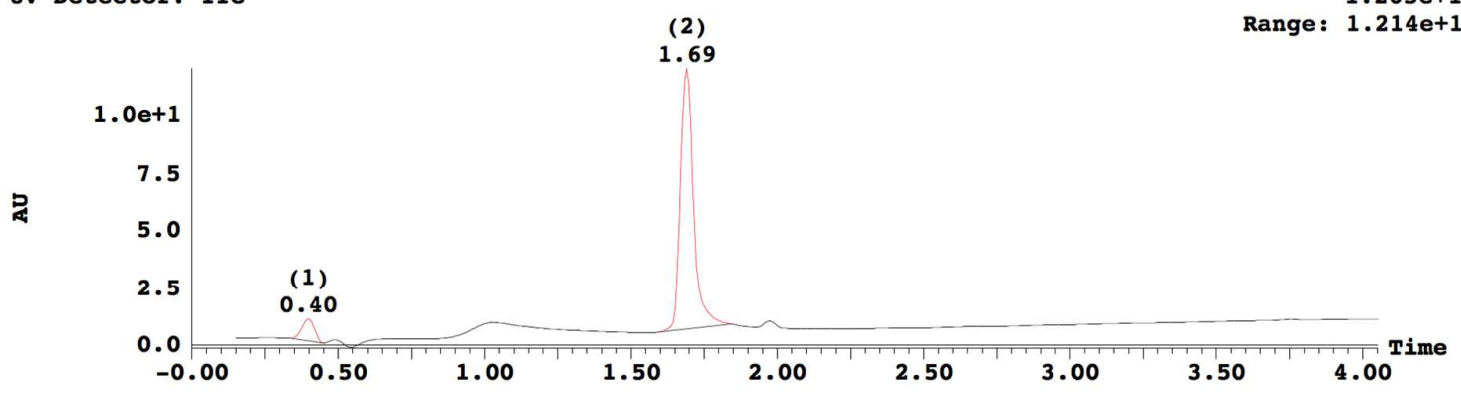

\section{Peptide 3:}

uv Detector: TIC

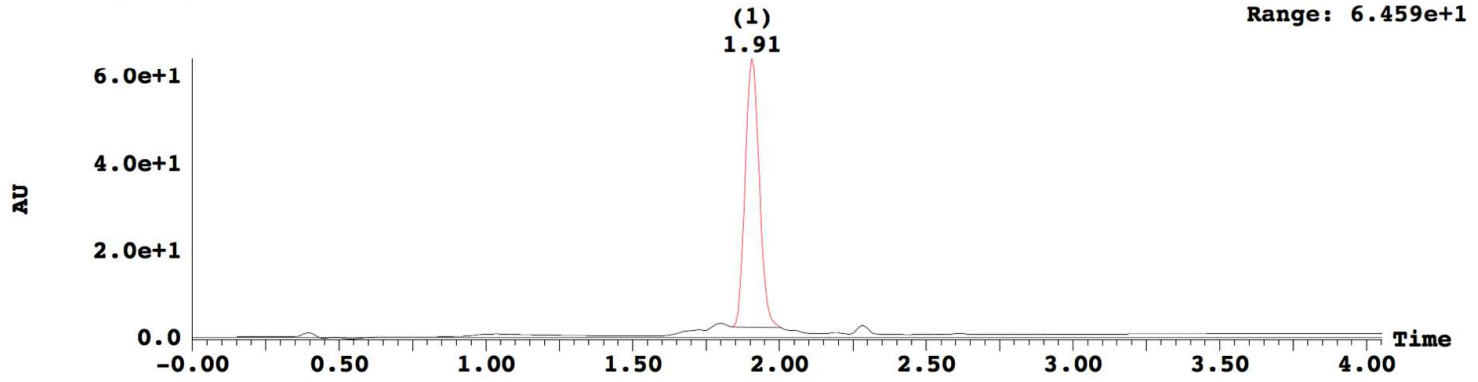

Peptide 4:

UV Detector: TIC $\quad 3.656 \mathrm{e}+1$

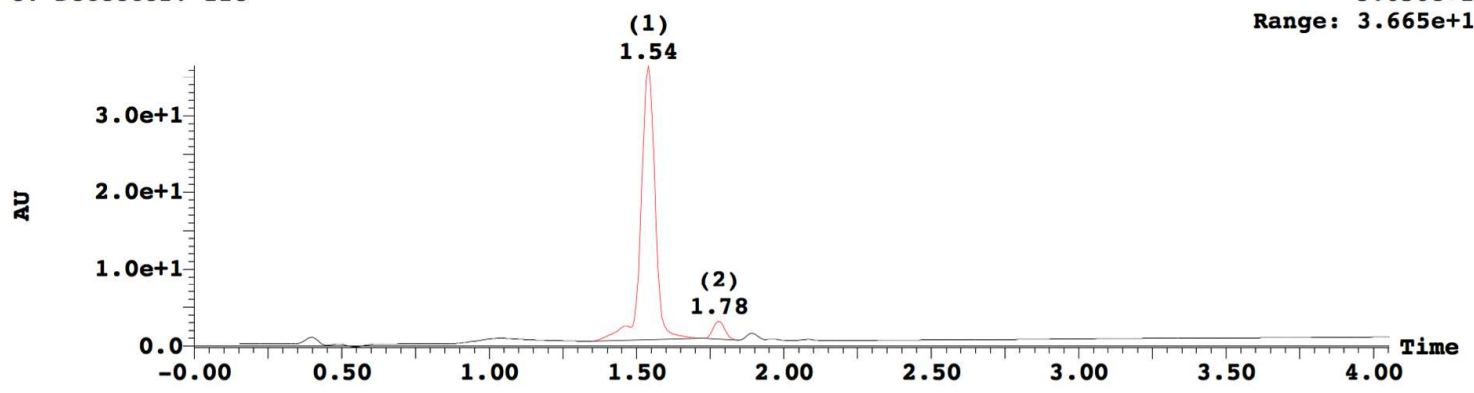

M7Nle :

UV Detector: TIC
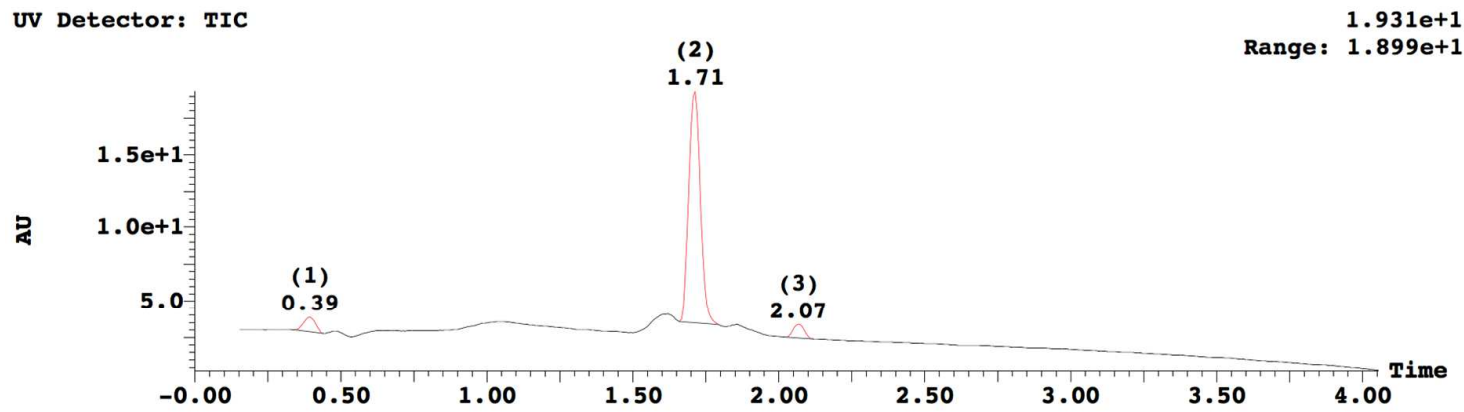
R2A:

UV Detector: TIC

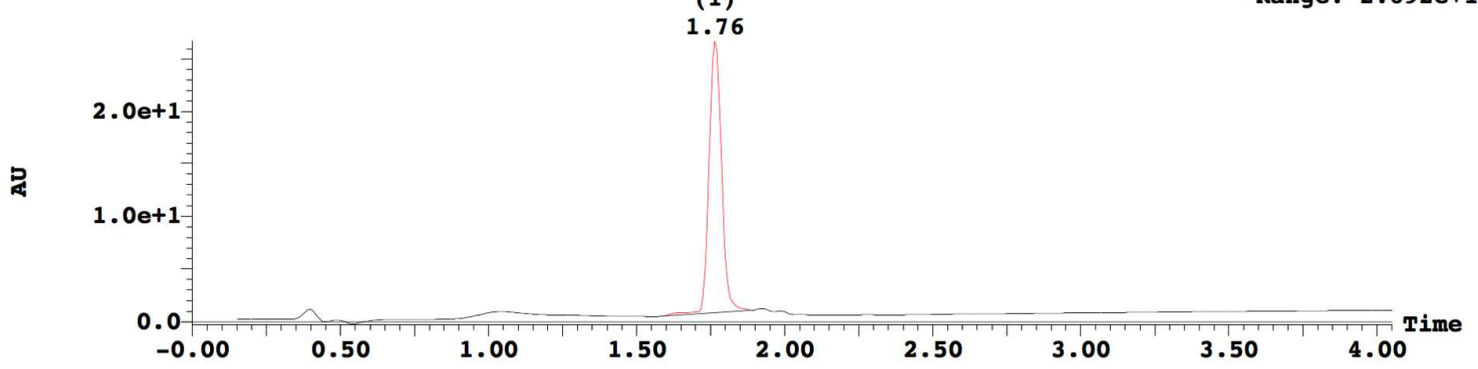

F3A:

UV Detector: TIC

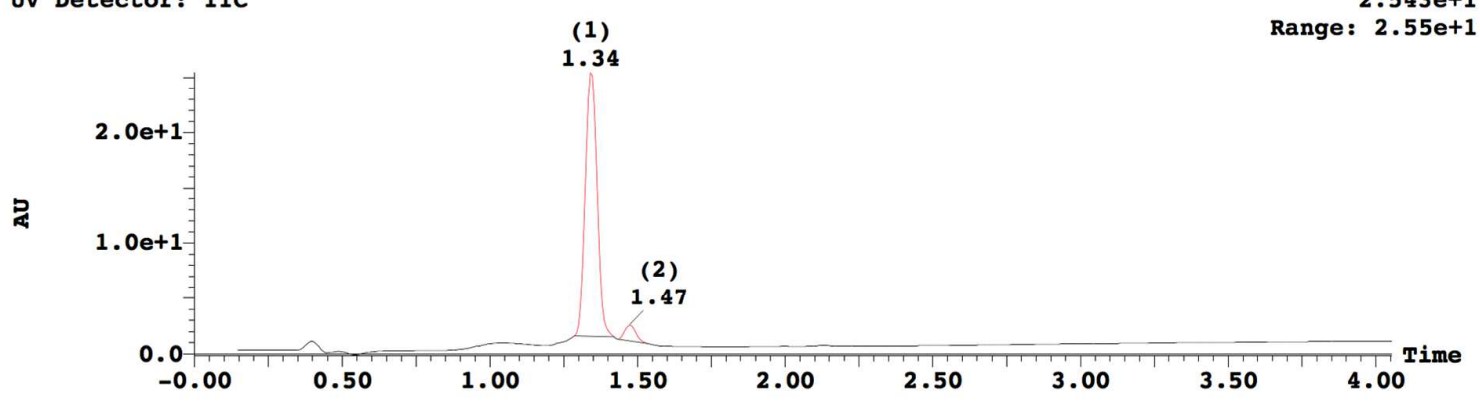

Y4A:

UV Detector: TIC

$1.583 e+1$

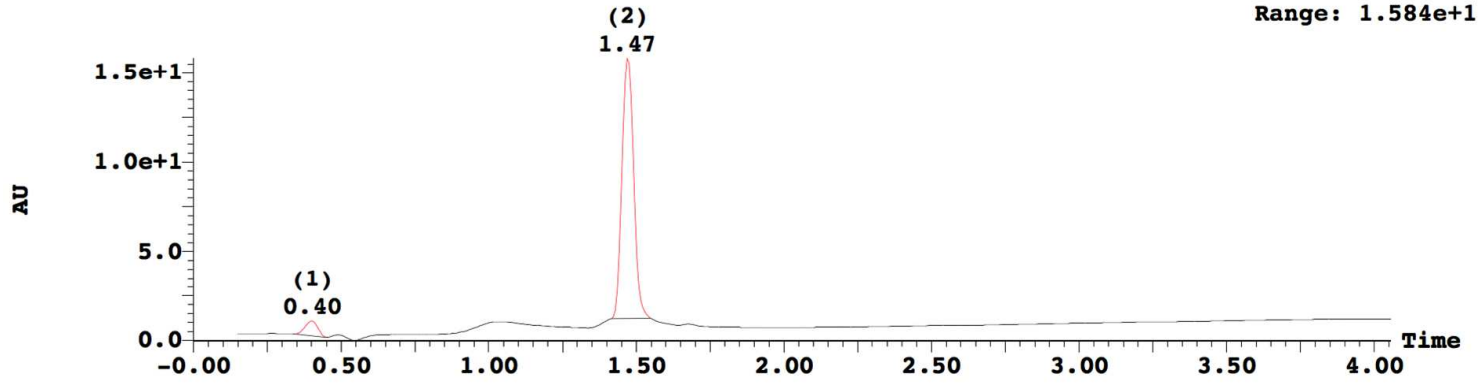

V5A:

UV Detector: TIC

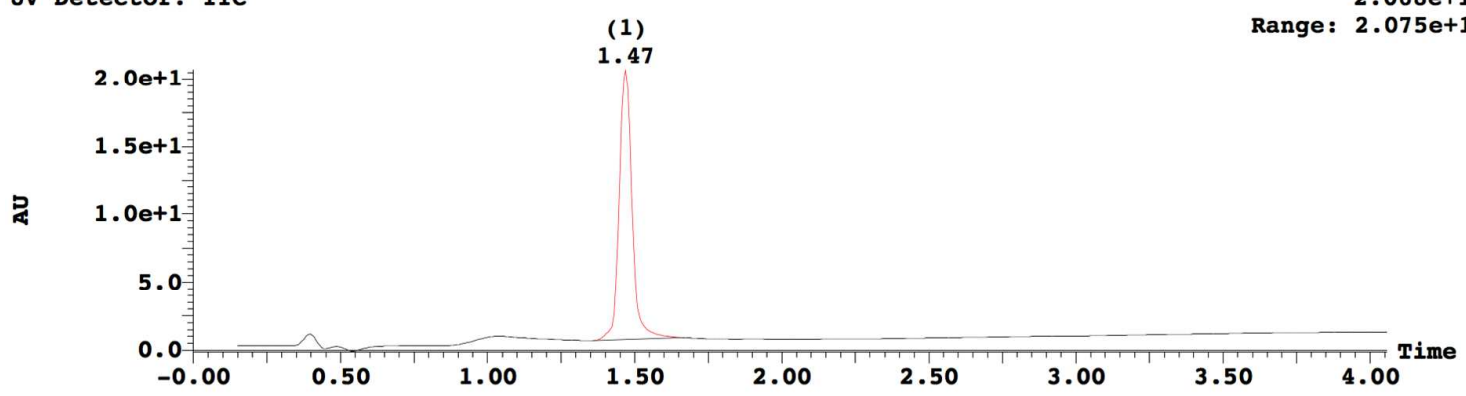


V6A:

UV Detector: TIC

$1.395 e+1$

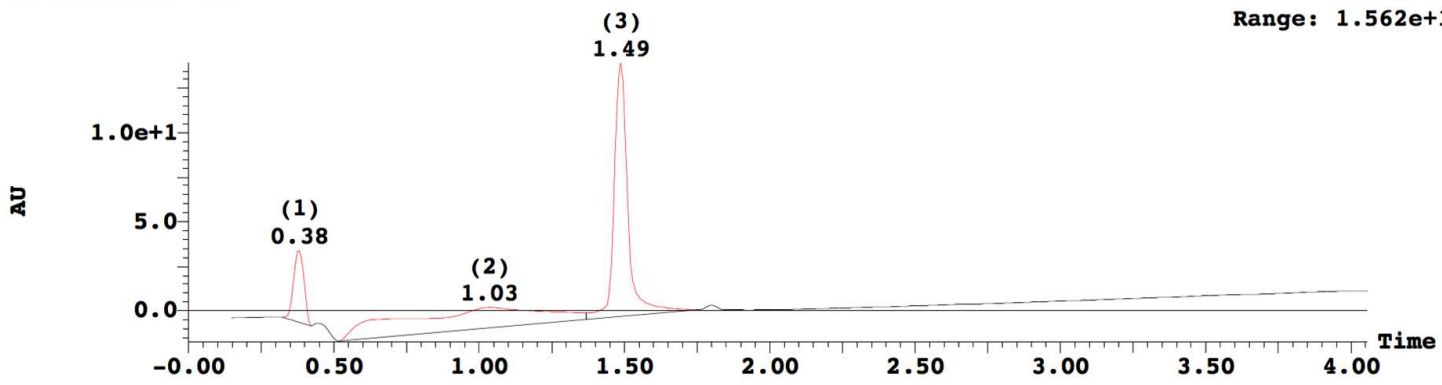

M7A:

UV Detector: TIC

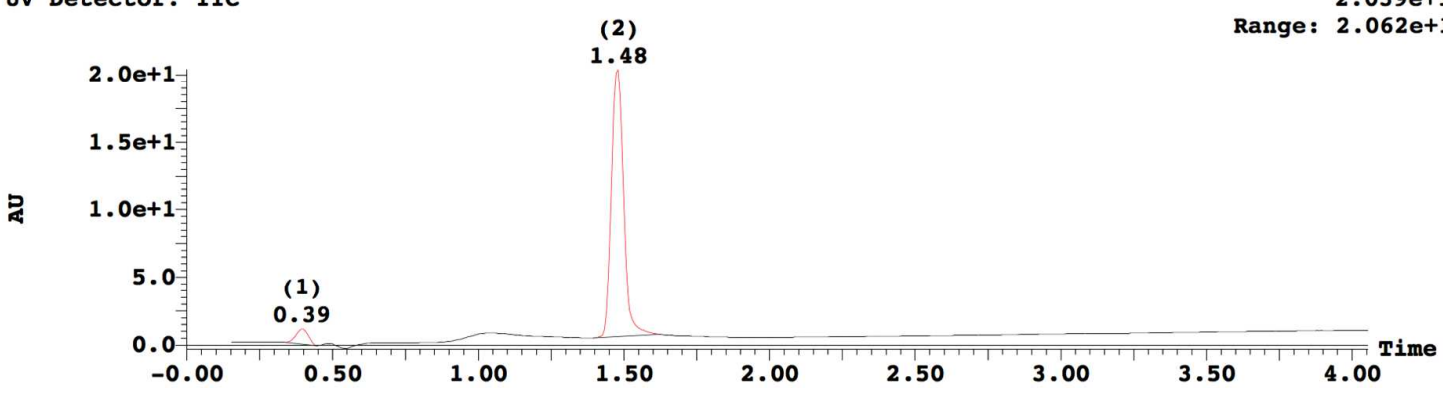

W8A:

UV Detector: TIC

$1.191 \mathrm{e}+1$

UV Detector: TIC

1.28

Range: $1.224 e+1$

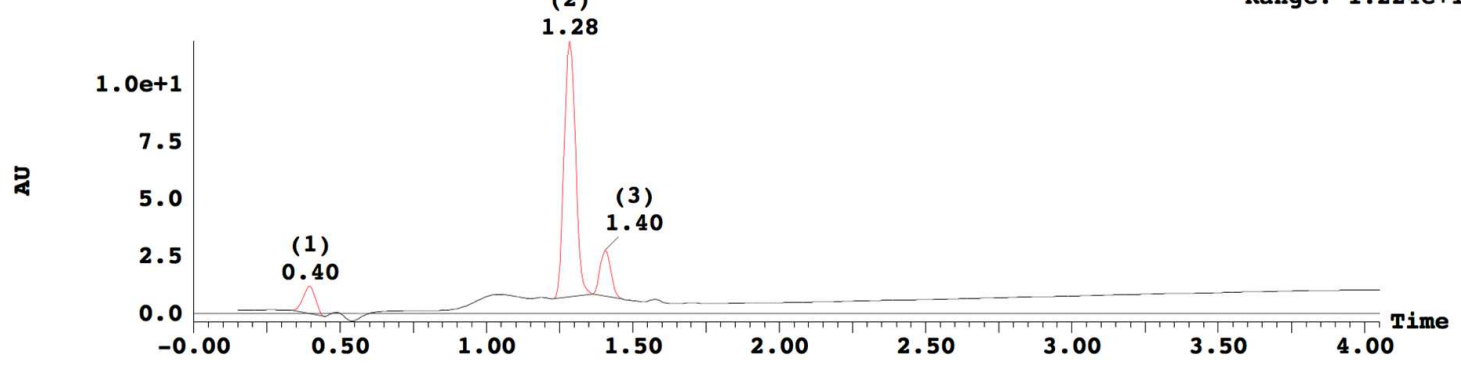

K9A:

UV Detector: TIC

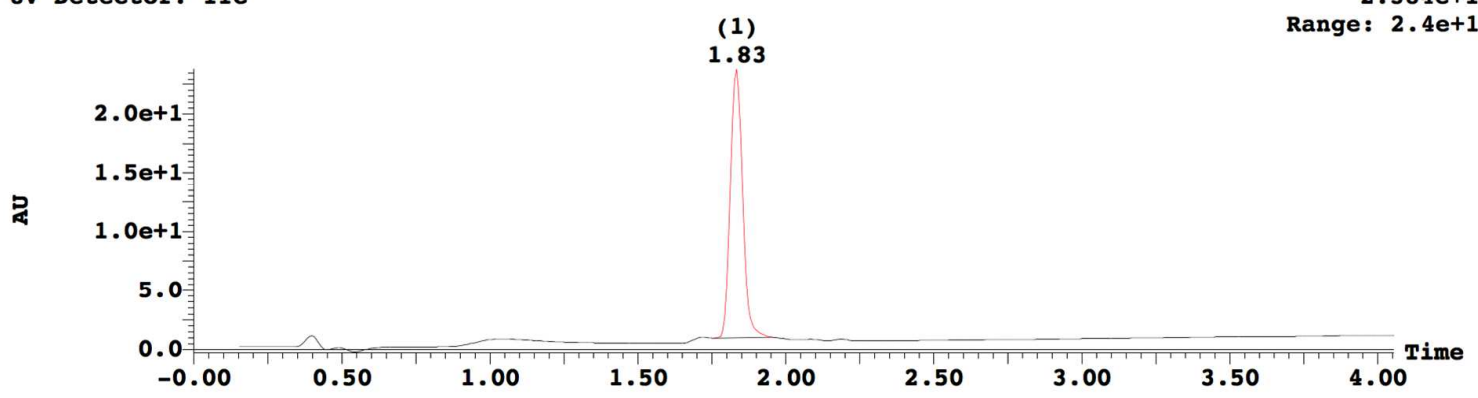


2) CD spectra

CD spectroscopy performed in PBS or in water

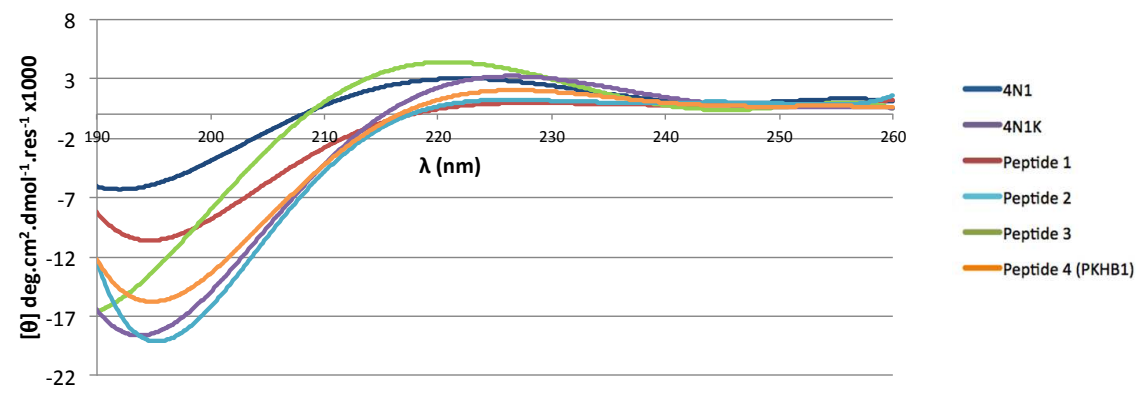

Peptides were dissolved at 50 ? $\mathrm{M}$ concentration in a $10 \mathrm{mM}$ sodium phosphate buffer at $\mathrm{pH} 7.4$

\section{NMR tables}

Table S1. ${ }^{1 \mathrm{H}},{ }^{13} \mathrm{C},{ }^{15} \mathrm{~N}$ chemical shifts of $4 \mathrm{~N} 1 \mathrm{~K}$ peptide $(500 \mathrm{MHz}, 298 \mathrm{~K}, \mathrm{pH}$ )

\begin{tabular}{|c|c|c|c|c|c|c|}
\hline $\begin{array}{l}\text { Residu } \\
\text { e }\end{array}$ & ${ }^{15} \mathrm{~N}$ & ${ }^{1} \mathrm{HN}$ & ${ }^{13} \mathrm{C} \alpha$ & ${ }^{1} \mathrm{H} \alpha$ & ${ }^{13} \mathrm{CO}$ & Side chain resonances \\
\hline Lys1 & & & 55.6 & 3.98 & 182.2 & $\begin{array}{l}{ }^{13} \mathrm{C} \beta 33.3 ;{ }^{13} \mathrm{C} \gamma 23.9 ;{ }^{13} \mathrm{C} \delta 29.2 ;{ }^{13} \mathrm{C} \varepsilon 42.1 \\
{ }^{1} \mathrm{H} \beta 1.83 ;{ }^{1} \mathrm{H} \gamma 1.32 ;{ }^{1} \mathrm{H} \delta 1.66 ;{ }^{1} \mathrm{H} \varepsilon 2.94\end{array}$ \\
\hline Arg2 & $\begin{array}{l}123 . \\
8\end{array}$ & 8.62 & 56.0 & 4.32 & 175.1 & $\begin{array}{l}{ }^{13} \mathrm{C} \beta 31.2 ;{ }^{13} \mathrm{C} \gamma 27.0 ;{ }^{13} \mathrm{C} \delta 43.4 ;{ }^{13} \mathrm{C} \zeta 159.6 ;{ }^{15} \mathrm{~N} \varepsilon \\
84.7 ;{ }^{1} \mathrm{H} \beta 1.67 ;{ }^{1} \mathrm{H} \gamma 1.53,1.44 ;{ }^{1} \mathrm{H} \delta 3.13 ;{ }^{1} \mathrm{H} \varepsilon 7.07\end{array}$ \\
\hline Phe3 & $\begin{array}{l}123 . \\
0\end{array}$ & 8.44 & 57.6 & 4.61 & 175.0 & $\begin{array}{l}{ }^{13} \mathrm{C} \beta 40.2 ;{ }^{13} \mathrm{C} \gamma 138.9 ;{ }^{13} \mathrm{C} \delta 131.9 ;{ }^{13} \mathrm{C} \varepsilon 131.5 ;{ }^{13} \mathrm{C} \zeta \\
129.9 ;{ }^{1} \mathrm{H} \beta 3.03,2.97 ;{ }^{1} \mathrm{H} \delta 7.22 ;{ }^{1} \mathrm{H} \varepsilon 7.33 ;{ }^{1} \mathrm{H} \zeta \\
7.30\end{array}$ \\
\hline Tyr4 & $\begin{array}{l}123 . \\
2\end{array}$ & 8.15 & 57.5 & 4.56 & 174.6 & $\begin{array}{l}{ }^{13} \mathrm{C} \beta 39.4 ;{ }^{13} \mathrm{C} \gamma 130.6 ;{ }^{13} \mathrm{C} \delta 133.3 ;{ }^{13} \mathrm{C} \varepsilon 118.2 ;{ }^{13} \mathrm{C} \zeta \\
157.2 ;{ }^{1} \mathrm{H} \beta 2.94,2.83 ;{ }^{1} \mathrm{H} \delta 7.06 ;{ }^{1} \mathrm{H} \varepsilon 6.77\end{array}$ \\
\hline Val5 & $\begin{array}{l}123 . \\
3\end{array}$ & 8.04 & 62.1 & 4.01 & 175.4 & $\begin{array}{l}{ }^{13} \mathrm{C} \beta 33.0 ;{ }^{13} \mathrm{C} \gamma 20.9 ;{ }^{13} \mathrm{C} \gamma \text { 目 } 21.1 ;{ }^{1} \mathrm{H} \beta \quad 1.94 ;{ }^{1} \mathrm{H} \gamma \\
0.91 ;{ }^{1} \mathrm{H} \gamma \text { ? } 0.86\end{array}$ \\
\hline Val6 & $\begin{array}{l}125 . \\
2\end{array}$ & 8.19 & 62.4 & 3.94 & 175.8 & $\begin{array}{l}{ }^{13} \mathrm{C} \beta 32.8 ;{ }^{13} \mathrm{C} \gamma 20.9 ;{ }^{13} \mathrm{C} \gamma \text { 回 } 21.0 ;{ }^{1} \mathrm{H} \beta \quad 1.90 ;{ }^{1} \mathrm{H} \gamma \\
0.89 ;{ }^{1} \mathrm{H} \gamma \text { ? } 0.76\end{array}$ \\
\hline Met7 & $\begin{array}{l}125 . \\
0\end{array}$ & 8.34 & 55.1 & 4.46 & 175.5 & $\begin{array}{l}{ }^{13} \mathrm{C} \beta 32.9 ;{ }^{13} \mathrm{C} \gamma 32.0 ;{ }^{13} \mathrm{C} \varepsilon 16.9 ;{ }^{1} \mathrm{H} \beta 1.93 ;{ }^{1} \mathrm{H} \gamma 2.52, \\
2.44 ;{ }^{1} \mathrm{H} \varepsilon 2.05\end{array}$ \\
\hline Trp8 & $\begin{array}{l}123 . \\
1\end{array}$ & 8.09 & 57.2 & 4.65 & 175.5 & 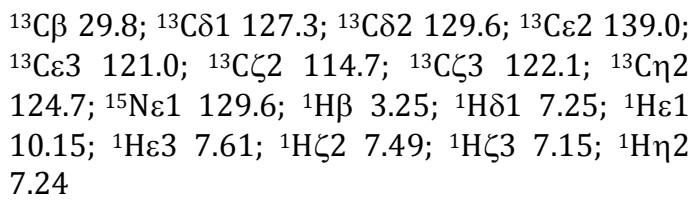 \\
\hline Lys9 & $\begin{array}{l}123 . \\
9\end{array}$ & 8.01 & 56.1 & 4.23 & 175.1 & $\begin{array}{l}{ }^{13} \mathrm{C} \beta 33.5 ;{ }^{13} \mathrm{C} \gamma 24.5 ;{ }^{13} \mathrm{C} \delta 29.2 ;{ }^{13} \mathrm{C} \varepsilon \\
1.74,1.61 ;{ }^{1} \mathrm{H} \gamma 1.29 ;{ }^{1} \mathrm{H} \delta 1.61 ;{ }^{1} \mathrm{H} \varepsilon \\
1.95\end{array}$ \\
\hline Lys10 & $\begin{array}{l}127 . \\
3\end{array}$ & 7.98 & 57.2 & 4.09 & 180.4 & $\begin{array}{l}{ }^{13} \mathrm{C} \beta 33.4 ;{ }^{13} \mathrm{C} \gamma 24.8 ;{ }^{13} \mathrm{C} \delta 29.2 ;{ }^{13} \mathrm{C} \varepsilon 42.2 ;{ }^{1} \mathrm{H} \beta \\
1.79,1.69 ;{ }^{1} \mathrm{H} \gamma 1.39 ;{ }^{1} \mathrm{H} \delta 1.67 ;{ }^{1} \mathrm{H} \varepsilon 2.97\end{array}$ \\
\hline
\end{tabular}


Table S2. ${ }^{1 \mathrm{H}},{ }^{13} \mathrm{C},{ }^{15} \mathrm{~N}$ chemical shifts of peptide 4 (500 MHz, 298K, pH 5)

\begin{tabular}{|c|c|c|c|c|c|c|}
\hline $\begin{array}{l}\text { Residu } \\
\text { e }\end{array}$ & ${ }^{15} \mathrm{~N}$ & ${ }^{1} \mathrm{HN}$ & ${ }^{13} \mathrm{C} \alpha$ & ${ }^{1} \mathrm{H} \alpha$ & ${ }^{13} \mathrm{CO}$ & Side chain resonances \\
\hline D-Lys1 & & & 55.9 & 4.04 & 182.8 & $\begin{array}{l}{ }^{13} \mathrm{C} \beta 33.3 ;{ }^{13} \mathrm{C} \gamma 24.2 ;{ }^{13} \mathrm{C} \delta 29.3 ;{ }^{13} \mathrm{C} \varepsilon 42.0 \\
{ }^{1} \mathrm{H} \beta 1.92 ;{ }^{1} \mathrm{H} \gamma 1.45 ;{ }^{1} \mathrm{H} \delta 1.72 ;{ }^{1} \mathrm{H} \varepsilon 3.01\end{array}$ \\
\hline Arg2 & $\begin{array}{l}123 . \\
5\end{array}$ & 8.79 & 56.5 & 4.27 & 175.5 & $\begin{array}{l}{ }^{13} \mathrm{C} \beta \quad 31.1 ;{ }^{13} \mathrm{C} \gamma \quad 27.1 ;{ }^{13} \mathrm{C} \delta \quad 43.3 ;{ }^{15} \mathrm{~N} \varepsilon \text { 84.8; } \\
{ }^{1} \mathrm{H} \beta \quad 1.66 ;{ }^{1} \mathrm{H} \gamma 1.44 ;{ }^{1} \mathrm{H} \delta 3.11 ;{ }^{1} \mathrm{H} \varepsilon 7.12\end{array}$ \\
\hline Phe3 & $\begin{array}{l}121 . \\
9\end{array}$ & 8.37 & 57.6 & 4.67 & 174.9 & $\begin{array}{l}{ }^{13} \mathrm{C} \beta 40.0 ;{ }^{13} \mathrm{C} \gamma 138.8 ;{ }^{13} \mathrm{C} \delta 131.9 ;{ }^{13} \mathrm{C} \varepsilon \text { 131.5; }{ }^{13} \mathrm{C} \zeta \\
129.9 ;{ }^{1} \mathrm{H} \beta 3.04,2.99 ;{ }^{1} \mathrm{H} \delta 7.20 ;{ }^{1} \mathrm{H} \varepsilon 7.32 ;{ }^{1} \mathrm{H} \zeta \\
7.29\end{array}$ \\
\hline Tyr4 & $\begin{array}{l}123 . \\
3\end{array}$ & 8.11 & 57.5 & 4.58 & 174.7 & $\begin{array}{l}{ }^{13} \mathrm{C} \beta 39.4 ;{ }^{13} \mathrm{C} \gamma 130.6 ;{ }^{13} \mathrm{C} \delta 133.3 ;{ }^{13} \mathrm{C} \varepsilon 118.2 ;{ }^{13} \mathrm{C} \zeta \\
157.2 ;{ }^{1} \mathrm{H} \beta 2.90,2.84 ;{ }^{1} \mathrm{H} \delta 7.03 ;{ }^{1} \mathrm{H} \varepsilon 6.78\end{array}$ \\
\hline Val5 & $\begin{array}{l}123 . \\
1\end{array}$ & 8.03 & 62.1 & 4.03 & 175.4 & $\begin{array}{l}{ }^{13} \mathrm{C} \beta 33.0 ;{ }^{13} \mathrm{C} \gamma 20.9 ;{ }^{13} \mathrm{C} \gamma \text { 回 } 21.2 ;{ }^{1} \mathrm{H} \beta \quad 1.94 ;{ }^{1} \mathrm{H} \gamma \\
0.90 ;{ }^{1} \mathrm{H} \gamma \text { 回 } 0.86\end{array}$ \\
\hline Val6 & $\begin{array}{l}124 . \\
8\end{array}$ & 8.18 & 62.4 & 3.99 & 175.9 & $\begin{array}{l}{ }^{13} \mathrm{C} \beta 32.8 ;{ }^{13} \mathrm{C} \gamma 20.9 ;{ }^{13} \mathrm{C} \gamma \text { 回 } 21.1 ;{ }^{1} \mathrm{H} \beta \quad 1.90 ;{ }^{1} \mathrm{H} \gamma \\
0.89 ;{ }^{1} \mathrm{H} \gamma \text { 回 } 0.75\end{array}$ \\
\hline Met7 & $\begin{array}{l}124 . \\
8\end{array}$ & 8.36 & 55.2 & 4.48 & 175.7 & $\begin{array}{l}{ }^{13} \mathrm{C} \beta 33.0 ;{ }^{13} \mathrm{C} \gamma 32.0 ;{ }^{13} \mathrm{C} \varepsilon 16.9 ;{ }^{1} \mathrm{H} \beta 1.96,1.90 ;{ }^{1} \mathrm{H} \gamma \\
2.50,2.43 ;{ }^{1} \mathrm{H} \varepsilon 2.04\end{array}$ \\
\hline \multirow[t]{2}{*}{ Trp8 } & $\begin{array}{l}122 . \\
6\end{array}$ & 8.10 & 57.2 & 4.68 & 175.9 & 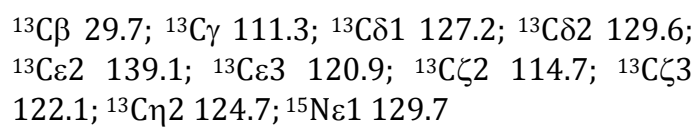 \\
\hline & & & & & & $\begin{array}{l}{ }^{1} \mathrm{H} \beta 3.29,3.24 ;{ }^{1} \mathrm{H} \delta 17.24 ;{ }^{1} \mathrm{H} \varepsilon 110.11 ;{ }^{1} \mathrm{H} \varepsilon 37.60 ; \\
{ }^{1} \mathrm{H} \zeta 2 \text { 7.48; }{ }^{1} \mathrm{H} \zeta 3 \text { 7.13; }{ }^{1} \mathrm{H} \eta 2 ~ 7.23\end{array}$ \\
\hline Lys9 & $\begin{array}{l}123 . \\
4\end{array}$ & 8.07 & 56.5 & 4.24 & 175.2 & $\begin{array}{l}{ }^{13} \mathrm{C} \beta 33.7 ;{ }^{13} \mathrm{C} \gamma 24.7 ;{ }^{13} \mathrm{C} \delta 29.1 ;{ }^{13} \mathrm{C} \varepsilon \text { 42.2; }{ }^{1} \mathrm{H} \beta \\
1.71,1.59 ;{ }^{1} \mathrm{H} \gamma 1.26 ;{ }^{1} \mathrm{H} \delta 1.60 ;{ }^{1} \mathrm{H} \varepsilon 2.93\end{array}$ \\
\hline D-Lys10 & $\begin{array}{l}125 . \\
6\end{array}$ & 7.57 & 57.6 & 4.09 & 180.9 & $\begin{array}{l}{ }^{13} \mathrm{C} \beta 33.9 ;{ }^{13} \mathrm{C} \gamma 24.7 ;{ }^{13} \mathrm{C} \delta 22.2 ;{ }^{13} \mathrm{C} \varepsilon \quad 42.2 ;{ }^{1} \mathrm{H} \beta \\
1.76,1.62 ;{ }^{1} \mathrm{H} \gamma 1.31 ;{ }^{1} \mathrm{H} \delta 1.63 ;{ }^{1} \mathrm{H} \varepsilon 2.95\end{array}$ \\
\hline
\end{tabular}


Table S3. ${ }^{1} \mathrm{H},{ }^{13} \mathrm{C}$, ${ }^{15} \mathrm{~N}$ chemical shifts of Peptide 2 (500 MHz, 298K, pH 5)

\begin{tabular}{|c|c|c|c|c|c|c|}
\hline $\begin{array}{l}\text { Residu } \\
\text { e }\end{array}$ & ${ }^{15} \mathrm{~N}$ & ${ }^{1} \mathrm{HN}$ & ${ }^{13} \mathrm{C} \alpha$ & ${ }^{1} \mathrm{H} \alpha$ & ${ }^{13} \mathrm{CO}$ & Side chain resonances \\
\hline Ac & & & 24.5 & 2.04 & 177.2 & \\
\hline Lys1 & $\begin{array}{l}127 . \\
1\end{array}$ & 8.24 & 56.7 & 4.17 & 176.9 & $\begin{array}{l}{ }^{13} \mathrm{C} \beta 33.1 ;{ }^{13} \mathrm{C} \gamma 24.9 ;{ }^{13} \mathrm{C} \delta 29.2 ;{ }^{13} \mathrm{C} \varepsilon 42.2 \\
{ }^{1} \mathrm{H} \beta 1.67 ;{ }^{1} \mathrm{H} \gamma 1.39,1.34 ;{ }^{1} \mathrm{H} \delta 1.66 ;{ }^{1} \mathrm{H} \varepsilon 2.96\end{array}$ \\
\hline Arg2 & $\begin{array}{l}122 . \\
0\end{array}$ & 8.28 & 55.9 & 4.26 & 175.7 & $\begin{array}{l}{ }^{13} \mathrm{C} \beta \quad 30.9 ;{ }^{13} \mathrm{C} \gamma \quad 26.9 ;{ }^{13} \mathrm{C} \delta \quad 43.3 ;{ }^{15} \mathrm{~N} \varepsilon \text { 85.0; } \\
{ }^{1} \mathrm{H} \beta \quad 1.63 ;{ }^{1} \mathrm{H} \gamma 1.45,1.42 ;{ }^{1} \mathrm{H} \delta 3.10 ;{ }^{1} \mathrm{H} \varepsilon 7.09\end{array}$ \\
\hline Phe3 & $\begin{array}{l}121 . \\
3\end{array}$ & 8.18 & 57.6 & 4.59 & 175.0 & $\begin{array}{l}{ }^{13} \mathrm{C} \beta 39.9 ;{ }^{13} \mathrm{C} \gamma 138.9 ;{ }^{13} \mathrm{C} \delta 131.9 ;{ }^{13} \mathrm{C} \varepsilon 131.5 ;{ }^{13} \mathrm{C} \zeta \\
129.9 ;{ }^{1} \mathrm{H} \beta 3.04,2.94 ;{ }^{1} \mathrm{H} \delta 7.19 ;{ }^{1} \mathrm{H} \varepsilon 7.32 ;{ }^{1} \mathrm{H} \zeta \\
7.28\end{array}$ \\
\hline Tyr4 & $\begin{array}{l}122 . \\
2\end{array}$ & 8.06 & 57.7 & 4.56 & 175.0 & $\begin{array}{l}{ }^{13} \mathrm{C} \beta 39.2 ;{ }^{13} \mathrm{C} \gamma 130.6 ;{ }^{13} \mathrm{C} \delta 133.3 ;{ }^{13} \mathrm{C} \varepsilon 118.2 ;{ }^{13} \mathrm{C} \zeta \\
157.2 ;{ }^{1} \mathrm{H} \beta 2.96,2.87 ;{ }^{1} \mathrm{H} \delta 7.06 ;{ }^{1} \mathrm{H} \varepsilon 6.79\end{array}$ \\
\hline Val5 & $\begin{array}{l}122 . \\
8\end{array}$ & 8.00 & 62.2 & 4.01 & 175.6 & $\begin{array}{l}{ }^{13} \mathrm{C} \beta 33.0 ;{ }^{13} \mathrm{C} \gamma 20.9 ;{ }^{13} \mathrm{C} \gamma \text { 回 } 21.2 ;{ }^{1} \mathrm{H} \beta \quad 1.95 ;{ }^{1} \mathrm{H} \gamma \\
0.91 ;{ }^{1} \mathrm{H} \gamma \text { 回 } 0.86\end{array}$ \\
\hline Val6 & $\begin{array}{l}124 . \\
5\end{array}$ & 8.14 & 62.5 & 3.96 & 176.0 & $\begin{array}{l}{ }^{13} \mathrm{C} \beta 32.7 ;{ }^{13} \mathrm{C} \gamma \quad 20.9 ;{ }^{13} \mathrm{C} \gamma \text { 回 } 21.1 ;{ }^{1} \mathrm{H} \beta \quad 1.91 ;{ }^{1} \mathrm{H} \gamma \\
0.89 ;{ }^{1} \mathrm{H} \gamma \text { 回 } 0.77\end{array}$ \\
\hline Met7 & $\begin{array}{l}124 . \\
6\end{array}$ & 8.32 & 55.3 & 4.44 & 175.7 & $\begin{array}{l}{ }^{13} \mathrm{C} \beta 32.9 ;{ }^{13} \mathrm{C} \gamma 31.9 ;{ }^{13} \mathrm{C} \varepsilon 16.9 ;{ }^{1} \mathrm{H} \beta 1.93 ;{ }^{1} \mathrm{H} \gamma 2.48, \\
2.44 ;{ }^{1} \mathrm{H} \varepsilon 2.05\end{array}$ \\
\hline Trp8 & $\begin{array}{l}122 . \\
7\end{array}$ & 8.07 & n.d. & 4.65 & 175.9 & 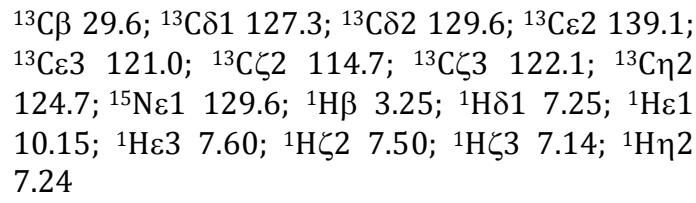 \\
\hline Lys9 & $\begin{array}{l}123 . \\
3\end{array}$ & 8.01 & 56.0 & 4.20 & 175.8 & $\begin{array}{l}{ }^{13} \mathrm{C} \beta 33.4 ;{ }^{13} \mathrm{C} \gamma 24.6 ;{ }^{13} \mathrm{C} \delta 29.2 ;{ }^{13} \mathrm{C} \varepsilon \text { 42.2; }{ }^{1} \mathrm{H} \beta \\
1.71,1.59 ;{ }^{1} \mathrm{H} \gamma 1.24 ;{ }^{1} \mathrm{H} \delta 1.61 ;{ }^{1} \mathrm{H} \varepsilon 2.93\end{array}$ \\
\hline Lys10 & $\begin{array}{l}123 . \\
5\end{array}$ & 8.11 & 56.4 & 4.12 & n.d. & $\begin{array}{l}{ }^{13} \mathrm{C} \beta 33.1 ;{ }^{13} \mathrm{C} \gamma 24.9 ;{ }^{13} \mathrm{C} \delta 29.2 ;{ }^{13} \mathrm{C} \varepsilon \text { 42.2; }{ }^{1} \mathrm{H} \beta \\
1.78,1.70 ;{ }^{1} \mathrm{H} \gamma 1.42 ;{ }^{1} \mathrm{H} \delta 1.67 ;{ }^{1} \mathrm{H} \varepsilon 2.98\end{array}$ \\
\hline $\mathrm{NH}_{2}$ & $\begin{array}{l}108 . \\
8\end{array}$ & $\begin{array}{l}7.58 \\
7.10\end{array}$ & & & & \\
\hline
\end{tabular}


S10

Table S4. ${ }^{1} \mathrm{H},{ }^{13} \mathrm{C}$, ${ }^{15} \mathrm{~N}$ chemical shifts of $4 \mathrm{NGG}$ peptide $(500 \mathrm{MHz}, 298 \mathrm{~K}, \mathrm{pH}$ )

\begin{tabular}{|c|c|c|c|c|c|c|}
\hline $\begin{array}{l}\text { Residu } \\
\text { e }\end{array}$ & ${ }^{15} \mathrm{~N}$ & ${ }^{1} \mathrm{HN}$ & ${ }^{13} \mathrm{C} \alpha$ & ${ }^{1} \mathrm{H} \alpha$ & ${ }^{13} \mathrm{CO}$ & Side chain resonances \\
\hline Lys1 & & & 55.7 & 4.05 & 182.3 & $\begin{array}{l}{ }^{13} \mathrm{C} \beta \quad 33.4 ;{ }^{13} \mathrm{C} \gamma \quad 24.0 ;{ }^{13} \mathrm{C} \delta \quad 29.3 ;{ }^{13} \mathrm{C} \varepsilon \text { 42.0; } \\
{ }^{1} \mathrm{H} \beta \quad 1.85 ;{ }^{1} \mathrm{H} \gamma \quad 1.35 ;{ }^{1} \mathrm{H} \delta \quad 1.63 ;{ }^{1} \mathrm{H} \varepsilon 2.89\end{array}$ \\
\hline Arg2 & n.d. & 8.71 & 56.1 & 4.37 & 174.8 & $\begin{array}{l}{ }^{13} \mathrm{C} \beta 31.5 ;{ }^{13} \mathrm{C} \gamma \quad 27.0 ;{ }^{13} \mathrm{C} \delta \quad 43.4 ;{ }^{1} \mathrm{H} \beta 1.66 ;{ }^{1} \mathrm{H} \gamma \\
1.50,1.44 ;{ }^{1} \mathrm{H} \delta 3.10 ;{ }^{1} \mathrm{H} \varepsilon 7.09\end{array}$ \\
\hline Phe3 & $\begin{array}{l}123 . \\
2\end{array}$ & 8.47 & 57.5 & 4.59 & 175.1 & $\begin{array}{l}{ }^{13} \mathrm{C} \beta 40.2 ;{ }^{13} \mathrm{C} \gamma 138.9 ;{ }^{13} \mathrm{C} \delta 131.9 ;{ }^{13} \mathrm{C} \varepsilon 131.3 ;{ }^{13} \mathrm{C} \zeta \\
129.8 ;{ }^{1} \mathrm{H} \beta \quad 2.92,2.71 ;{ }^{1} \mathrm{H} \delta 7.03 ;{ }^{1} \mathrm{H} \varepsilon 7.26 ;{ }^{1} \mathrm{H} \zeta \\
7.25\end{array}$ \\
\hline Tyr4 & $\begin{array}{l}123 . \\
9\end{array}$ & 8.31 & 57.9 & 4.52 & 175.8 & $\begin{array}{l}{ }^{13} \mathrm{C} \beta 39.4 ;{ }^{13} \mathrm{C} \gamma 130.7 ;{ }^{13} \mathrm{C} \delta 133.3 ;{ }^{13} \mathrm{C} \varepsilon 118.2 ;{ }^{13} \mathrm{C} \zeta \\
157.3 ;{ }^{1} \mathrm{H} \beta 2.97,2.83 ;{ }^{1} \mathrm{H} \delta 7.05 ;{ }^{1} \mathrm{H} \varepsilon 6.78\end{array}$ \\
\hline Gly5 & $\begin{array}{l}111 . \\
2\end{array}$ & 8.05 & 45.6 & 3.82 & 174.6 & \\
\hline Gly6 & $\begin{array}{l}107 . \\
8\end{array}$ & 7.89 & 45.4 & $\begin{array}{l}3.89 \\
3.81\end{array}$ & 174.0 & \\
\hline Met7 & $\begin{array}{l}119 . \\
6\end{array}$ & 7.98 & 55.5 & 4.42 & 175.4 & $\begin{array}{l}{ }^{13} \mathrm{C} \beta 33.2 ;{ }^{13} \mathrm{C} \gamma 31.7 ;{ }^{13} \mathrm{C} \varepsilon 16.9 ;{ }^{1} \mathrm{H} \beta 1.91,1.87 ;{ }^{1} \mathrm{H} \gamma \\
2.38 ;{ }^{1} \mathrm{H} \varepsilon 2.03\end{array}$ \\
\hline Trp8 & $\begin{array}{l}121 . \\
9\end{array}$ & 8.14 & 57.1 & 4.70 & 175.8 & 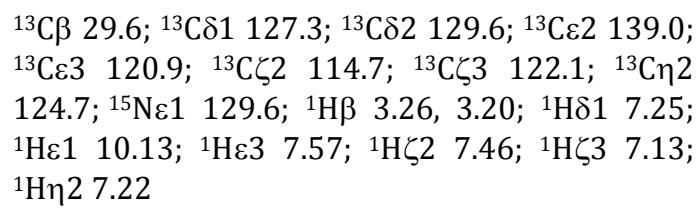 \\
\hline Lys9 & $\begin{array}{l}124 . \\
0\end{array}$ & 8.12 & 56.0 & 4.28 & 175.0 & $\begin{array}{l}{ }^{13} \mathrm{C} \beta 33.5 ;{ }^{13} \mathrm{C} \gamma 24.5 ;{ }^{13} \mathrm{C} \delta 229.2 ;{ }^{13} \mathrm{C} \varepsilon \text { 42.2; }{ }^{1} \mathrm{H} \beta \\
1.77,1.61 ;{ }^{1} \mathrm{H} \gamma 1.29 ;{ }^{1} \mathrm{H} \delta 1.60 ;{ }^{1} \mathrm{H} \varepsilon 2.93\end{array}$ \\
\hline Lys10 & $\begin{array}{l}128 . \\
2\end{array}$ & 7.89 & 58.1 & 4.04 & 181.3 & $\begin{array}{l}{ }^{13} \mathrm{C} \beta 33.6 ;{ }^{13} \mathrm{C} \gamma 24.9 ;{ }^{13} \mathrm{C} \delta 29.3 ;{ }^{13} \mathrm{C} \varepsilon \text { 42.2; }{ }^{1} \mathrm{H} \beta \\
1.77,1.68 ;{ }^{1} \mathrm{H} \gamma 1.38 ;{ }^{1} \mathrm{H} \delta 1.67 ;{ }^{1} \mathrm{H} \varepsilon 2.97\end{array}$ \\
\hline
\end{tabular}




\section{S11}

Table S5. Partial ${ }^{1} \mathrm{H}$ assignments of $4 \mathrm{~N} 1$ peptide ( $500 \mathrm{MHz}, 298 \mathrm{~K}, \mathrm{pH}$ )

\begin{tabular}{llll}
$\begin{array}{l}\text { Residu } \\
\mathrm{e}\end{array}$ & ${ }^{1} \mathrm{HN}$ & ${ }^{1} \mathrm{H} \alpha$ & Side chain resonances \\
\hline Arg1 & & \\
Phe2 & & & ${ }^{1} \mathrm{H} \delta 7.23 ;{ }^{1} \mathrm{H} \varepsilon 7.34$ \\
Tyr3 & & & ${ }^{1} \mathrm{H} \delta 7.07 ;{ }^{1} \mathrm{H} \varepsilon 6.78$ \\
Val4/5 & 8.24 & 4.07 & ${ }^{1} \mathrm{H} \beta 1.96 ;{ }^{1} \mathrm{H} \gamma 0.90 ;{ }^{1} \mathrm{H} \gamma$ 回 0.81 \\
Val4/5 & 8.12 & 4.05 & ${ }^{1} \mathrm{H} \beta 2.01 ;{ }^{1} \mathrm{H} \gamma 0.94 ;{ }^{1} \mathrm{H} \gamma$ [ 0.90 \\
Met6 & 8.43 & 4.50 & ${ }^{1} \mathrm{H} \beta 1.95 ;{ }^{1} \mathrm{H} \gamma 2.53$ \\
Trp7 & 8.22 & 4.70 & ${ }^{1} \mathrm{H} \beta 3.24 ;{ }^{1} \mathrm{H} \delta 17.26 ;{ }^{1} \mathrm{H} \varepsilon 110.17 ;{ }^{1} \mathrm{H} \varepsilon 37.67 ;{ }^{1} \mathrm{H} \zeta 27.50 ;{ }^{1} \mathrm{H} \zeta 37.17 ;{ }^{1} \mathrm{H} \eta 2$ \\
& & & 7.25 \\
Lys8 & 7.59 & 4.00 & \\
& &
\end{tabular}

Table S6. ${ }^{1} \mathrm{H}$ chemical shifts of peptide 1 (500 MHz, 298K, pH 5)

\begin{tabular}{lccl}
\hline $\begin{array}{l}\text { Residu } \\
\mathrm{e}\end{array}$ & ${ }^{1} \mathrm{HN}$ & ${ }^{1} \mathrm{H} \alpha$ & Side chain resonances \\
\hline Ac & & & \\
Arg1 & 8.15 & 4.16 & ${ }^{1} \mathrm{H} \beta 1.58 ;{ }^{1} \mathrm{H} \gamma 1.42 ;{ }^{1} \mathrm{H} \delta 3.10 ;{ }^{1} \mathrm{H} \varepsilon 7.09$ \\
Phe2 & 8.15 & 4.62 & ${ }^{1} \mathrm{H} \beta 3.07,2.93 ;{ }^{1} \mathrm{H} \delta 7.18 ;{ }^{1} \mathrm{H} \varepsilon 7.31 ;{ }^{1} \mathrm{H} \zeta 7.29$ \\
Tyr3 & 8.02 & 4.55 & ${ }^{1} \mathrm{H} \beta 2.98,2.88 ;{ }^{1} \mathrm{H} \delta 7.07 ;{ }^{1} \mathrm{H} \varepsilon 6.80$ \\
Val4/5 & 7.95 & 4.00 & ${ }^{1} \mathrm{H} \beta 1.97 ;{ }^{1} \mathrm{H} \gamma 0.91 ;{ }^{1} \mathrm{H} \gamma 00.87$ \\
Val4/5 & 8.14 & 3.97 & ${ }^{1} \mathrm{H} \beta 1.93 ;{ }^{1} \mathrm{H} \gamma 0.91 ;{ }^{1} \mathrm{H} \gamma 00.81$ \\
Met6 & 8.32 & 4.44 & ${ }^{1} \mathrm{H} \beta 1.95 ;{ }^{1} \mathrm{H} \gamma 2.51,2.44 ;{ }^{1} \mathrm{H} \varepsilon 2.05^{*}$ \\
Trp7 & 8.14 & 4.65 & ${ }^{1} \mathrm{H} \beta 3.27 ;{ }^{1} \mathrm{H} \delta 17.24 ;{ }^{1} \mathrm{H} \varepsilon 110.15 ;{ }^{1} \mathrm{H} \varepsilon 37.64 ;{ }^{1} \mathrm{H} \zeta 2$ \\
& & & $7.50 ;{ }^{1} \mathrm{H} \zeta 37.16 ;{ }^{1} \mathrm{H} \eta 27.25$ \\
Lys8 & 8.02 & 4.15 & ${ }^{1} \mathrm{H} \beta 1.72,1.57 ;{ }^{1} \mathrm{H} \gamma 1.25 ;{ }^{1} \mathrm{H} \delta 1.58 ;{ }^{1} \mathrm{H} \varepsilon 2.93$ \\
\hline${ }^{*}$ ambiguous & &
\end{tabular}

Table S7. Partial ${ }^{1} \mathrm{H}$ assignments of peptide 3 (500 MHz, 298K, pH 5)

\begin{tabular}{|c|c|c|c|}
\hline Residue & ${ }^{1} \mathrm{HN}$ & ${ }^{1} \mathrm{H} \alpha$ & Side chain resonances \\
\hline$\beta^{2}$-Arg1 & & & $2.64 ; 1.07 ; 0.89 ;{ }^{1} \mathrm{H} \gamma 1.37 ;{ }^{1} \mathrm{H} \delta 2.92 ;{ }^{1} \mathrm{H} \varepsilon 6.99$ \\
\hline Phe2 & 8.50 & 4.70 & ${ }^{1} \mathrm{H} \beta 3.15,2.82 ;{ }^{1} \mathrm{H} \delta 7.24 ;{ }^{1} \mathrm{H} \varepsilon 7.34$ \\
\hline Tyr3 & 8.36 & 4.62 & ${ }^{1} \mathrm{H} \beta 3.00,2.95 ;{ }^{1} \mathrm{H} \delta 7.11 ;{ }^{1} \mathrm{H} \varepsilon 6.82$ \\
\hline Val4 & 8.06 & 4.04 & ${ }^{1} \mathrm{H} \beta 1.95 ;{ }^{1} \mathrm{H} \gamma 0.89$ \\
\hline Val5 & 8.17 & 3.94 & ${ }^{1} \mathrm{H} \beta$ 1.90; ${ }^{1} \mathrm{H} \gamma \quad 0.90 ;{ }^{1} \mathrm{H} \gamma$ 回 0.79 \\
\hline Met6 & 8.32 & 4.45 & ${ }^{1} \mathrm{H} \beta$ 1.94; ${ }^{1} \mathrm{H} \gamma 2.51,2.45$ \\
\hline Trp7 & 8.09 & 4.50 & $\begin{array}{l}{ }^{1} \mathrm{H} \beta 3.23 ;{ }^{1} \mathrm{H} \delta 1 \text { 7.24; }{ }^{1} \mathrm{H} \varepsilon 1 \text { 10.14; }{ }^{1} \mathrm{H} \varepsilon 3 \text { 7.64; }{ }^{1} \mathrm{H} \zeta 2 \text { 7.50; }{ }^{1} \mathrm{H} \zeta 3 \quad 7.16 ;{ }^{1} \mathrm{H} \eta 2 \\
\end{array}$ \\
\hline$\beta^{3}$-Lys8 & 7.64 & 3.94 & ${ }^{1} \mathrm{H} \beta 1.87 ;{ }^{1} \mathrm{H} \varepsilon 2.91 ; 1.59 ; 1.46 ; 1.28$ \\
\hline
\end{tabular}




\section{Binding affinity measurements by Biolayer Interferometry (BI) and Microscale Thermophoresis (MT)}

\section{Protocols:}

BI:

Typically, the biosensors were pre-equilibrated in PBS containing either biotinylated membranes or biocytine $100 \mu \mathrm{g} / \mathrm{mL}$. Biosensors are then equilibrated in assay buffer for $10 \mathrm{~min}$, brought to baseline in assay buffer for $60 \mathrm{sec}$. and transferred to wells containing peptide in dose-response (association for $120 \mathrm{sec}$. and dissociation for $300 \mathrm{sec}$.). The double reference with either membrane-loaded biosensors without any peptide dose-response or biocytine-loaded biosensors with each peptide dose-response were run in parallele for background signal substractions. Binding kinetics were calculated using the FortéBio Data Analysis v8.2 software.

MST:

The concentration of the NT.115-labeled membrane was kept constant, while the concentrations of the peptides were varied. After a short incubation $(5 \mathrm{mn})$ the samples were loaded into MST premium glass capillaries and the MST analysis was performed using the Monolith NT.115.

\begin{tabular}{|c|c|c|}
\hline Peptides & $\mathrm{Kd}(\mathrm{BI})$ & Kd (MST) \\
\hline 4N1 & NPD & NPD \\
\hline 4N1K & $19 \pm 1.6 \mu \mathrm{M}$ & $2.28+/-0.22 \mu \mathrm{M}$ \\
\hline 4NGG & NPD & NPD \\
\hline 1 & $1.5 \pm 0.59 \mu \mathrm{M}$ & $0,771 \pm 0,07 \mu \mathrm{M}$ \\
\hline 2 & $40 \pm 24 \mu \mathrm{M}$ & $1,2 \pm 0,16 \mu \mathrm{M}$ \\
\hline 3 & NPD & NPD \\
\hline 4 & $43 \pm 21 \mu \mathrm{M}$ & $3.04+/-0.25 \mu \mathrm{M}$ \\
\hline M/Nle & $18 \pm 0.60 \mu \mathrm{M}$ & ND \\
\hline R2A & $6.2 \pm 1.9 \mu \mathrm{M}$ & ND \\
\hline F3A & NPD & ND \\
\hline Y4A & NPD & ND \\
\hline V5A & NPD & ND \\
\hline V6A & NPD & ND \\
\hline M7A & $42 \pm 21 \mu \mathrm{M}$ & ND \\
\hline W8A & NPD & ND \\
\hline K9A & $27 \pm 21 \mu \mathrm{M}$ & ND \\
\hline
\end{tabular}

Table 2: Reported apparent Kd values with associated standard deviations $(\mathrm{N}=2 ; 3$ or 4). NPD : Non Pertinent Data. ND: Not determined. 


\section{S13}

\section{Binding Curves observed by Octet-Red}
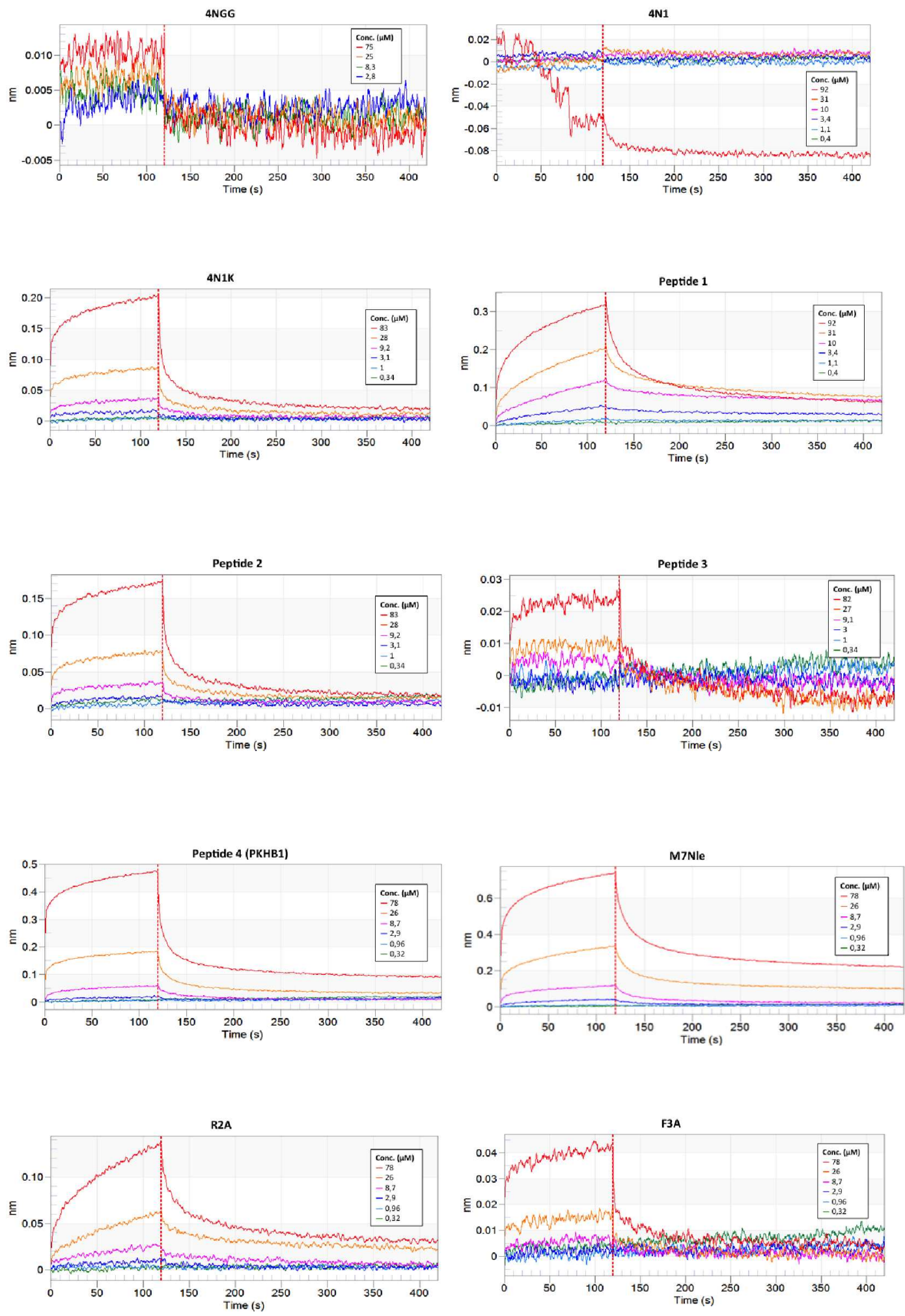

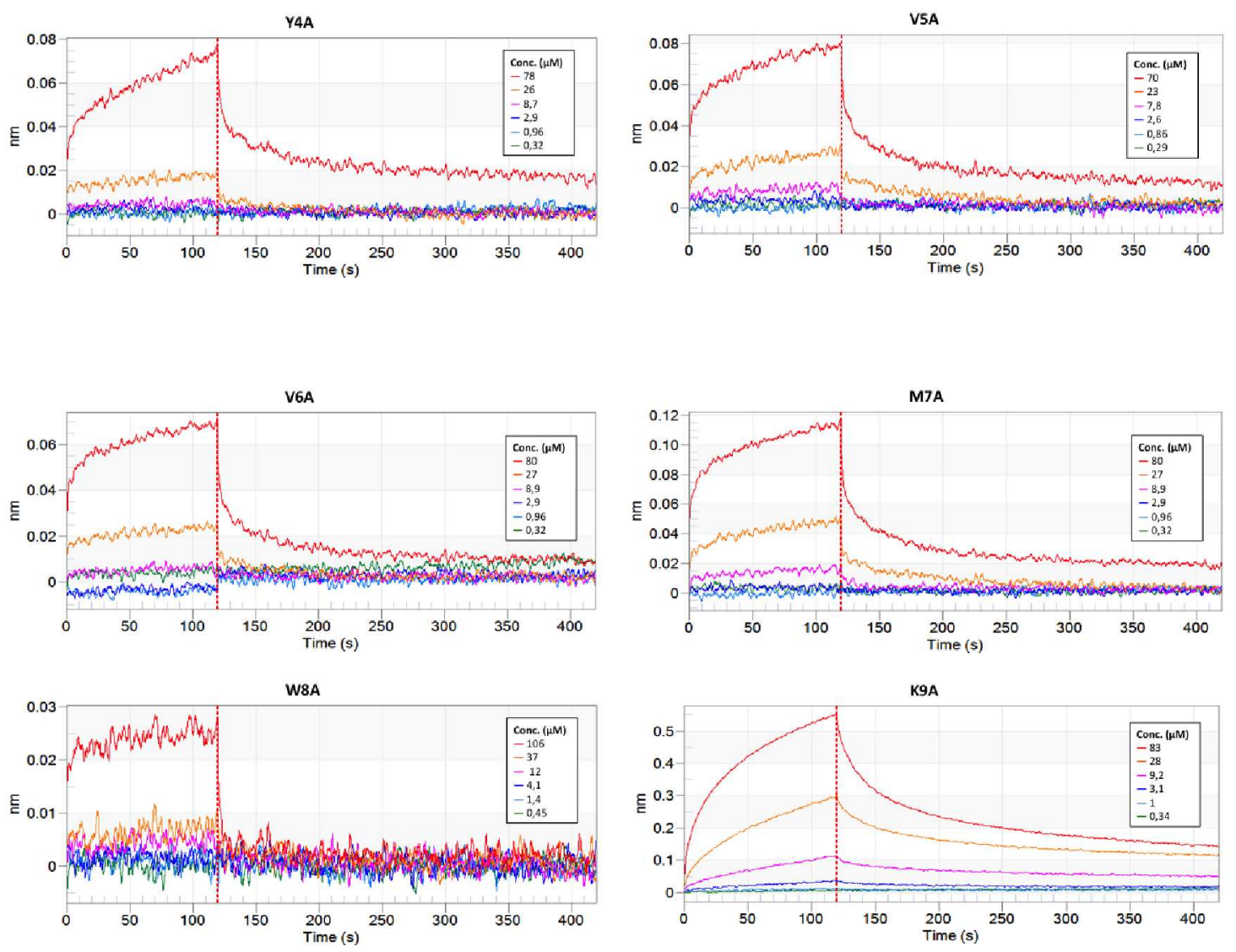

\section{Binding Curves observed by Microscale Thermophoresis}

For all peptides evaluated by MST, we have kept the concentration of the NT.115-labeled membrane constant, while the concentration of the ligand (peptide) was varied. After a short incubation the samples were loaded into MST premium glass capillaries and the MST analysis was performed using the Monolith NT.115. All concentrations are in $\mu \mathrm{M}$. 
NT.115: Mb versus 4N1:

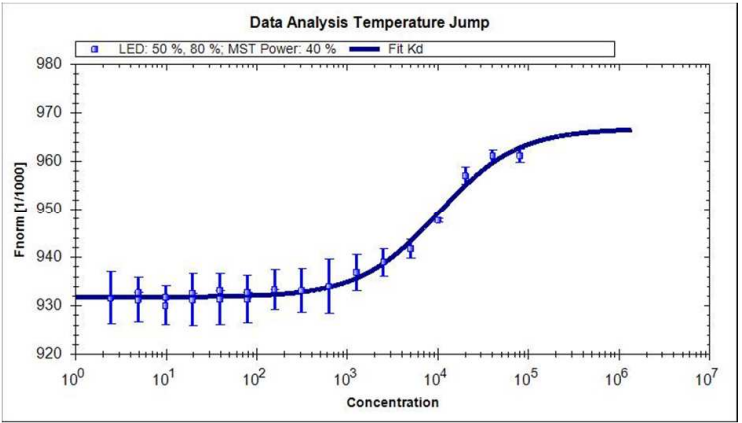

A $K_{d}$ of $10 \pm 0,8 \mu \mathrm{M}$ was determined for this interaction.

\section{NT.115: Mb versus 4NGG:}

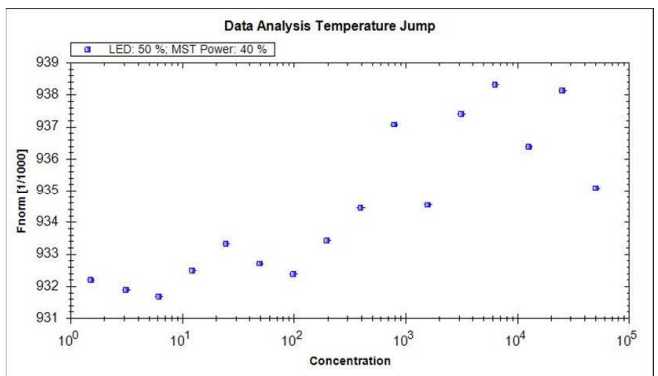

No binding was observed for this interaction.

NT.115: Mb versus 4N1K:

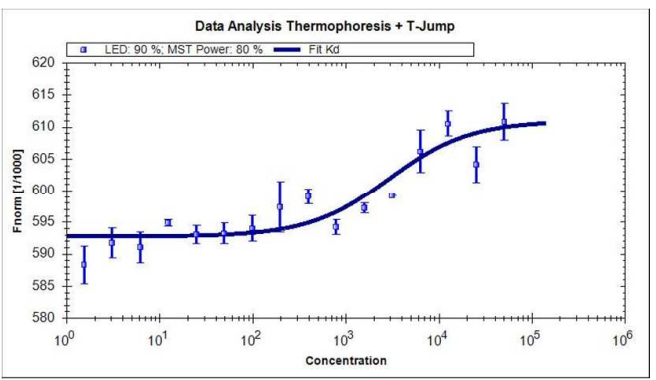

A $K_{d}$ of $2.88 \mu \mathrm{M}+/-0.52 \mu \mathrm{M}$ was determined for this interaction.

\section{NT.115: Mb versus Peptide 1:}

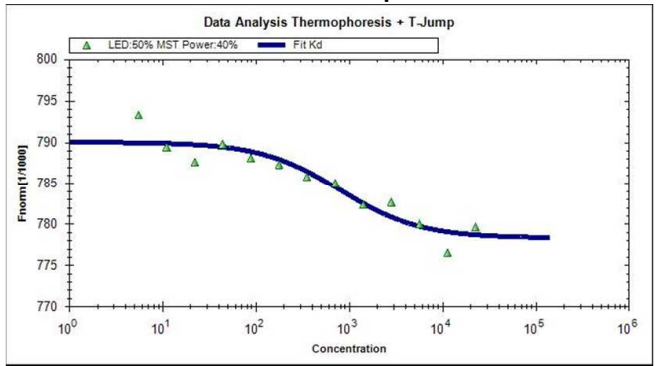

A $K d$ of $0,77 \mu \mathrm{M}+/-0.07 \mu \mathrm{M}$ was determined for this interaction. 
NT.115: Mb versus Peptide 2:

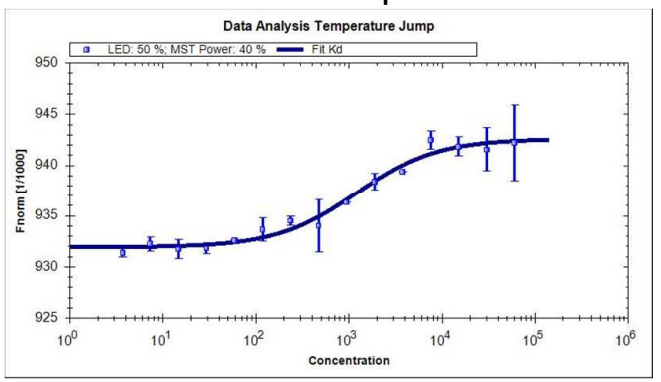

A $K_{d}$ of $1,2 \mu \mathrm{M}+/-0.16 \mu \mathrm{M}$ was determined for this interaction.

NT.115: Mb versus Peptide 3:

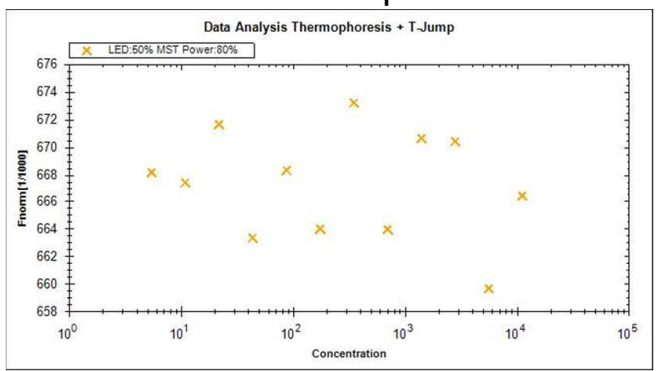

NT.115: Mb versus Peptide 4:

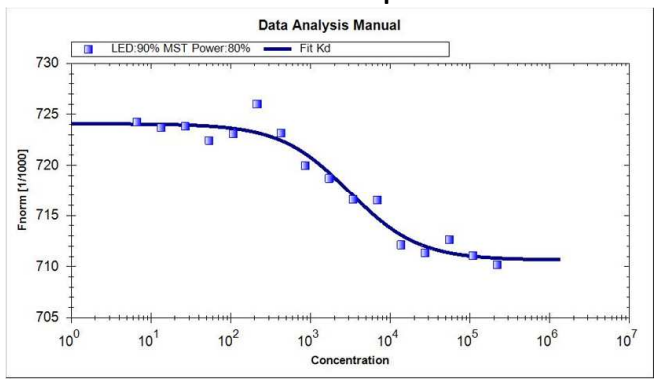

A $K_{d}$ of $3.04 \mu \mathrm{M}+/-0.25 \mu \mathrm{M}$ was determined for this interaction. 
S17

5. Cancer cell lines used in this manuscript

\begin{tabular}{|c|c|}
\hline Cancer & Cell Line \\
\hline Acute $\mathrm{T}$ cell leukemia & JURKAT \\
\hline Acute lymphoblastic leukemia & CEM \\
\hline Adenocarcinoma & MDA-MB-231 \\
\hline Breast adenocarcinoma & MCF-7 \\
\hline Breast adenocarcinoma & AU-565 \\
\hline $\begin{array}{l}\text { Breast epithelial cells with } \\
\text { transformed morphology }\end{array}$ & HBL-100 \\
\hline Burkitt's lymphoma & RAJI \\
\hline Burkitt's lymphoma & RAMOS \\
\hline B lymphocytic cell line & RPMI 8226 \\
\hline B lymphocytic cell line & RPMI 8866 \\
\hline Cervical cancer & HELA \\
\hline Chronic Lymphocytic Leukemia & MEC-1 \\
\hline Diffuse histiocytic lymphoma & U937 \\
\hline Immunoblastic B cell lymphoma & JM-1 \\
\hline Ovarian Carcinoma & OV10 \\
\hline Lung carcinoma & A549 \\
\hline Prostate cancer & LNCAP \\
\hline Colon carcinoma & HCT116 \\
\hline
\end{tabular}


MOLECULAR FORMULA STRINGS:

\begin{tabular}{|c|c|c|c|c|}
\hline Peptides & SMILES & $\begin{array}{c}\text { CD47 } \\
\text { Kd } \\
(\mu \mathrm{M})\end{array}$ & $\begin{array}{c}\text { MEC-1 } \\
\text { Cell } \\
\text { Death } \\
(\%), \\
2 \mathrm{~h}, \\
200 \mu \mathrm{M}\end{array}$ & $\begin{array}{l}\text { Serum } \\
\text { Stability }\end{array}$ \\
\hline $4 \mathrm{~N} 1$ & $\begin{array}{l}\mathrm{N}[\mathrm{C} @ @ \mathrm{H}](\mathrm{CCCNC}(\mathrm{N})=\mathrm{N}) \mathrm{C}(\mathrm{N}[\mathrm{C} @ @ \mathrm{H}](\mathrm{CC} 1=\mathrm{CC}=\mathrm{CC}=\mathrm{C} 1) \mathrm{C}(\mathrm{N}[\mathrm{C} @ @ \mathrm{H}](\mathrm{CC} 2=\mathrm{CC}=\mathrm{C}(\mathrm{O}) \mathrm{C}=\mathrm{C} 2) \mathrm{C}(\mathrm{N}[\mathrm{C} @ @ \mathrm{H}](\mathrm{C}(\mathrm{C}) \mathrm{C}) \mathrm{C}(\mathrm{N}[\mathrm{C} @ @ \mathrm{H}](\mathrm{C}(\mathrm{C}) \mathrm{C}) \mathrm{C}(\mathrm{N}[\mathrm{C} @ \\
@ \mathrm{H}](\mathrm{CCSC}) \mathrm{C}(\mathrm{N}[\mathrm{C} @ @ \mathrm{H}](\mathrm{CC}=\mathrm{CNC} 4=\mathrm{C} 3 \mathrm{C}=\mathrm{CC}=\mathrm{C} 4) \mathrm{C}(\mathrm{N}[\mathrm{C} @ @ \mathrm{H}](\mathrm{CCCCN}) \mathrm{C}(\mathrm{O})=\mathrm{O})=\mathrm{O})=\mathrm{O})=\mathrm{O})=\mathrm{O})=\mathrm{O})=\mathrm{O})=\mathrm{O}\end{array}$ & NPD & 13 & + \\
\hline 1 & $\begin{array}{l}\mathrm{O}=\mathrm{C}(\mathrm{N}[\mathrm{C} @ \mathrm{H}](\mathrm{C}(\mathrm{N}[\mathrm{C} @ \mathrm{H}](\mathrm{C}(\mathrm{N}[\mathrm{C} @ @ \mathrm{H}](\mathrm{C}(\mathrm{C}) \mathrm{C}) \mathrm{C}(\mathrm{N}[\mathrm{C} @ @ \mathrm{H}](\mathrm{C}(\mathrm{C}) \mathrm{C}) \mathrm{C}(\mathrm{N}[\mathrm{C} @ \mathrm{H}](\mathrm{C}(\mathrm{N}[\mathrm{C} @ \mathrm{H}](\mathrm{C}(\mathrm{N}[\mathrm{C} @ @ \mathrm{H}](\mathrm{CCCCN}) \mathrm{C}(\mathrm{N})=\mathrm{O})=\mathrm{O}) \mathrm{CC} 1=\mathrm{CNC} 2=\mathrm{C} 1 \mathrm{C}= \\
\mathrm{CC}=\mathrm{C} 2)=\mathrm{O}) \mathrm{CCSC})=\mathrm{O})=\mathrm{O})=\mathrm{O}) \mathrm{CC}=\mathrm{CC}=\mathrm{C}(\mathrm{O}) \mathrm{C}=\mathrm{C} 3)=\mathrm{O}) \mathrm{CC} 4=\mathrm{CC}=\mathrm{CC}=\mathrm{C} 4)[\mathrm{C} @ \mathrm{H}](\mathrm{CCCN} \mathrm{C}(\mathrm{N})=\mathrm{N}) \mathrm{NC}(\mathrm{C})=\mathrm{O}\end{array}$ & $\begin{array}{l}1.5 \pm \\
0.59\end{array}$ & 27 & ++ \\
\hline 3 & $\begin{array}{l}\mathrm{NC}[\mathrm{C} @ @ \mathrm{H}](\mathrm{CCCNC}(\mathrm{N})=\mathrm{N}) \mathrm{C}(\mathrm{N}[\mathrm{C} @ \mathrm{H}](\mathrm{C}(\mathrm{N}[\mathrm{C} @ \mathrm{H}](\mathrm{C}(\mathrm{N}[\mathrm{C} @ @ \mathrm{H}](\mathrm{C}(\mathrm{C}) \mathrm{C}) \mathrm{C}(\mathrm{N}[\mathrm{C} @ @ \mathrm{H}](\mathrm{C}(\mathrm{C}) \mathrm{C}) \mathrm{C}(\mathrm{N}[\mathrm{C} @ \mathrm{H}](\mathrm{C}(\mathrm{N}[\mathrm{C} @ \mathrm{H}](\mathrm{C}(\mathrm{N}[\mathrm{C} @ @ \mathrm{H}](\mathrm{CCCCN}) \mathrm{CC}(\mathrm{O})= \\
\mathrm{O})=\mathrm{O}) \mathrm{CC} 1=\mathrm{CNC} 2=\mathrm{C} 1 \mathrm{C}=\mathrm{CC}=\mathrm{C} 2)=\mathrm{O}) \mathrm{CCSC}=\mathrm{O})=\mathrm{O})=\mathrm{O}) \mathrm{CC} 3=\mathrm{CC}=\mathrm{C}(\mathrm{O}) \mathrm{C}=\mathrm{C} 3)=\mathrm{O}) \mathrm{CC} 4=\mathrm{CC}=\mathrm{CC}=\mathrm{C} 4)=\mathrm{O}\end{array}$ & NPD & NPD & ++ \\
\hline 4N1K & $\begin{array}{l}\mathrm{O}=\mathrm{C}(\mathrm{N}[\mathrm{C} @ @ \mathrm{H}](\mathrm{CCCCN}) \mathrm{C}(\mathrm{O})=\mathrm{O})[\mathrm{C} @ \mathrm{H}](\mathrm{CCCCN}) \mathrm{NC}([\mathrm{C} @ \mathrm{H}](\mathrm{CC} 1=\mathrm{CNNC2}=\mathrm{C} 1 \mathrm{C}=\mathrm{CC}=\mathrm{C} 2) \mathrm{NC}([\mathrm{C} @ \mathrm{H}](\mathrm{CCSC}) \mathrm{NC}([\mathrm{C} @ \mathrm{H}](\mathrm{C}(\mathrm{C}) \mathrm{C}) \mathrm{NC}([\mathrm{C} @ \mathrm{H}](\mathrm{C}(\mathrm{C}) \mathrm{C}) \\
\mathrm{NC}([\mathrm{C} @ \mathrm{H}](\mathrm{CC} 3=\mathrm{CC}=\mathrm{C}(\mathrm{O}) \mathrm{C}=\mathrm{C} 3) \mathrm{NC}([\mathrm{C} @ \mathrm{H}](\mathrm{CC} 4=\mathrm{CC}=\mathrm{CC}=\mathrm{C} 4) \mathrm{NC}([\mathrm{C} @ \mathrm{H}](\mathrm{CCCNC}(\mathrm{N})=\mathrm{N}) \mathrm{NC}([\mathrm{C} @ \mathrm{H}](\mathrm{CCCNN}) \mathrm{N})=\mathrm{O})=\mathrm{O})=\mathrm{O})=\mathrm{O})=\mathrm{O})=\mathrm{O})=\mathrm{O})=\mathrm{O}\end{array}$ & $\begin{array}{c}19 \pm \\
1.6 \\
\end{array}$ & 23 & - \\
\hline 4NGG & $\begin{array}{l}\mathrm{O}=\mathrm{C}(\mathrm{N}[\mathrm{C} @ @ \mathrm{H}](\mathrm{CCCCN}) \mathrm{C}(\mathrm{O})=\mathrm{O})[\mathrm{C} @ \mathrm{H}](\mathrm{CCCCN}) \mathrm{NC}([\mathrm{C} @ \mathrm{H}](\mathrm{CC} 1=\mathrm{CNC}=\mathrm{C} 1 \mathrm{C}=\mathrm{CC}=\mathrm{C} 2) \mathrm{NC}([\mathrm{C} @ \mathrm{H}](\mathrm{CCSC}) \mathrm{NC}(\mathrm{CNC}(\mathrm{CNC}([\mathrm{C} @ \mathrm{H}](\mathrm{CC} 3=\mathrm{CC}=\mathrm{C}(\mathrm{O}) \\
\mathrm{C}=\mathrm{C} 3) \mathrm{NC}([\mathrm{C} @ \mathrm{H}](\mathrm{CC} 4=\mathrm{CC}=\mathrm{CC}=\mathrm{C} 4) \mathrm{NC}([\mathrm{C} @ \mathrm{H}](\mathrm{CCCNC}(\mathrm{N})=\mathrm{N}) \mathrm{NC}([\mathrm{C} @ \mathrm{H}](\mathrm{CCCCN}) \mathrm{N})=\mathrm{O})=\mathrm{O})=\mathrm{O})=\mathrm{O})=\mathrm{O})=\mathrm{O})=\mathrm{O})=\mathrm{O}\end{array}$ & NPD & 2 & - \\
\hline 2 & 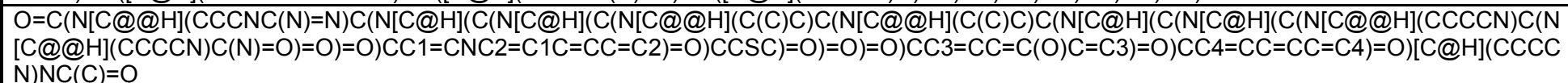 & $\begin{array}{c}40 \pm \\
24\end{array}$ & 30 & + \\
\hline 4 (PKHB1) & $\begin{array}{l}\mathrm{O}=\mathrm{C}(\mathrm{N}[\mathrm{C} @ \mathrm{H}](\mathrm{CCCCN}) \mathrm{C}(\mathrm{O})=\mathrm{O})[\mathrm{C} @ \mathrm{H}](\mathrm{CCCCN}) \mathrm{NC}([\mathrm{C} @ \mathrm{H}](\mathrm{CC} 1=\mathrm{CNC2}=\mathrm{C} 1 \mathrm{C}=\mathrm{CC}=\mathrm{C} 2) \mathrm{NC}([\mathrm{C} @ \mathrm{H}](\mathrm{CCSC}) \mathrm{NC}([\mathrm{C} @ \mathrm{H}](\mathrm{C}(\mathrm{C}) \mathrm{C}) \mathrm{NC}([\mathrm{C} @ \mathrm{H}](\mathrm{C}(\mathrm{C}) \mathrm{C}) \mathrm{NC} \\
([\mathrm{C} @ \mathrm{H}](\mathrm{CC} 3=\mathrm{CC}=\mathrm{C}(\mathrm{O}) \mathrm{C}=\mathrm{C} 3) \mathrm{NC}([\mathrm{C} @ \mathrm{H}](\mathrm{CC} 4=\mathrm{CC}=\mathrm{CC}=\mathrm{C} 4) \mathrm{NC}([\mathrm{C} @ \mathrm{H}](\mathrm{CCCNC}(\mathrm{N})=\mathrm{N}) \mathrm{NC}([\mathrm{C} @ \mathrm{H}](\mathrm{CCCCN}) \mathrm{N})=\mathrm{O})=\mathrm{O})=\mathrm{O})=\mathrm{O})=\mathrm{O})=\mathrm{O})=\mathrm{O})=\mathrm{O}\end{array}$ & $\begin{array}{c}43 \pm \\
21\end{array}$ & 63 & +++ \\
\hline R2A & $\begin{array}{l}\mathrm{N}[\mathrm{C} @ \mathrm{H}](\mathrm{CCCCN}) \mathrm{C}(\mathrm{N}[\mathrm{C} @ @ \mathrm{H}](\mathrm{C}) \mathrm{C}(\mathrm{N}[\mathrm{C} @ \mathrm{H}](\mathrm{C}(\mathrm{N}[\mathrm{C} @ \mathrm{H}](\mathrm{C}(\mathrm{N}[\mathrm{C} @ @ \mathrm{H}](\mathrm{C}(\mathrm{C}) \mathrm{C}) \mathrm{C}(\mathrm{N}[\mathrm{C} @ @ \mathrm{H}](\mathrm{C}(\mathrm{C}) \mathrm{C}) \mathrm{C}(\mathrm{N}[\mathrm{C} @ \mathrm{H}] \mathrm{C}(\mathrm{N}[\mathrm{C} @ \mathrm{H}](\mathrm{C}(\mathrm{N}[\mathrm{C} @(\mathrm{C}](\mathrm{CCCCN}) \mathrm{C} \\
(\mathrm{N}[\mathrm{C} @ \mathrm{H}](\mathrm{CCCCN}) \mathrm{C}(\mathrm{O})=\mathrm{O})=\mathrm{O})=\mathrm{O}) \mathrm{CC}=\mathrm{CN} 2=\mathrm{C} 1 \mathrm{C}=\mathrm{CC}=\mathrm{C} 2)=\mathrm{O}) \mathrm{CCSC}=\mathrm{C})=\mathrm{O})=\mathrm{O}) \mathrm{CC} 3=\mathrm{CC}=\mathrm{C}(\mathrm{O}) \mathrm{C}=\mathrm{C} 3)=\mathrm{O}) \mathrm{CC} 4=\mathrm{CC}=\mathrm{CC}=\mathrm{C} 4)=\mathrm{O})=\mathrm{O}\end{array}$ & $\begin{array}{c}6.2 \pm \\
1.9\end{array}$ & 44 & \\
\hline F3A & $\begin{array}{l}\mathrm{N}[\mathrm{C} @ \mathrm{H}](\mathrm{CCCCN}) \mathrm{C}(\mathrm{N}[\mathrm{C} @ @ \mathrm{H}](\mathrm{CCCNC}(\mathrm{N})=\mathrm{N}) \mathrm{C}(\mathrm{N}[\mathrm{C} @ \mathrm{H}](\mathrm{C}(\mathrm{N}[\mathrm{C} @ \mathrm{H}](\mathrm{C}(\mathrm{N}[\mathrm{C} @ @ \mathrm{H}](\mathrm{C}(\mathrm{C}) \mathrm{C}) \mathrm{C}(\mathrm{N}[\mathrm{C} @ @ \mathrm{H}](\mathrm{C}(\mathrm{C}) \mathrm{C}) \mathrm{C}(\mathrm{N}[\mathrm{C} @ \mathrm{H}](\mathrm{C}(\mathrm{N}[\mathrm{C} @ \mathrm{H}](\mathrm{C}(\mathrm{N}[\mathrm{C} @ @) \\
\mathrm{H}](\mathrm{CCCCN}) \mathrm{C}(\mathrm{N}[\mathrm{C} @ \mathrm{H}](\mathrm{CCCCN}) \mathrm{C}(\mathrm{O})=\mathrm{O})=\mathrm{O})=\mathrm{O}) \mathrm{CC} 1=\mathrm{CNN}=\mathrm{C} 1 \mathrm{C}=\mathrm{CC}=\mathrm{C} 2)=\mathrm{O}) \mathrm{CCSC})=\mathrm{O})=\mathrm{O})=\mathrm{O}) \mathrm{CC}=\mathrm{CC}=\mathrm{C}(\mathrm{O}) \mathrm{C}=\mathrm{C} 3)=\mathrm{O}) \mathrm{C})=\mathrm{O})=\mathrm{O}\end{array}$ & NPD & 6 & \\
\hline Y4A & $\begin{array}{l}\mathrm{N}[\mathrm{C} @ \mathrm{H}](\mathrm{CCCCN}) \mathrm{C}(\mathrm{N}[\mathrm{C} @ @ \mathrm{CH}](\mathrm{CCCNC}(\mathrm{N})=\mathrm{N}) \mathrm{C}(\mathrm{N}[\mathrm{C} @ \mathrm{H}](\mathrm{C}(\mathrm{N}[\mathrm{C} @ \mathrm{H}](\mathrm{C}(\mathrm{N}[\mathrm{C} @ @ \mathrm{H}](\mathrm{C}(\mathrm{C}) \mathrm{C}) \mathrm{C}(\mathrm{N}[\mathrm{C} @ @ \mathrm{H}](\mathrm{C}(\mathrm{C}) \mathrm{C}) \mathrm{C}(\mathrm{N}[\mathrm{C} @ \mathrm{H}](\mathrm{C}(\mathrm{N}[\mathrm{C} @ \mathrm{H}](\mathrm{C}(\mathrm{N}[\mathrm{C} @ @) \\
\mathrm{H}](\mathrm{CCCCN}) \mathrm{C}(\mathrm{N}[\mathrm{C} @ \mathrm{H}](\mathrm{CCCCN}) \mathrm{C}(\mathrm{O})=\mathrm{O})=\mathrm{O})=\mathrm{O}) \mathrm{CC} 1=\mathrm{CNC}=\mathrm{C} 1 \mathrm{C}=\mathrm{CC}=\mathrm{C} 2)=\mathrm{O}) \mathrm{CCSC}=\mathrm{O})=\mathrm{O})=\mathrm{O}) \mathrm{C})=\mathrm{O}) \mathrm{CC} 3=\mathrm{CC}=\mathrm{CC}=\mathrm{C} 3)=\mathrm{O})=\mathrm{O}\end{array}$ & NPD & 0 & \\
\hline V5A & $\begin{array}{l}\mathrm{N} N \mathrm{C} @ \mathrm{H}](\mathrm{CCCCN}) \mathrm{C}(\mathrm{N}[\mathrm{C} @ @ @ \mathrm{H}](\mathrm{CCCNC}(\mathrm{N})=\mathrm{N}) \mathrm{C}(\mathrm{N}[\mathrm{C} @ \mathrm{H}](\mathrm{C}(\mathrm{N}[\mathrm{C} @ \mathrm{H}](\mathrm{C}(\mathrm{N}[\mathrm{C} @ @ \mathrm{H}](\mathrm{C}(\mathrm{C}) \mathrm{C}) \mathrm{C}(\mathrm{N}[\mathrm{C} @ @ \mathrm{H}](\mathrm{C}(\mathrm{C}) \mathrm{C}) \mathrm{C}(\mathrm{N}[\mathrm{C} @ \mathrm{H}](\mathrm{C}(\mathrm{N}[\mathrm{C} @ \mathrm{H}](\mathrm{C}(\mathrm{N}[\mathrm{C} @ @) \\
\mathrm{H}](\mathrm{CCCCN}) \mathrm{C}(\mathrm{N}[\mathrm{C} @ \mathrm{H}](\mathrm{CCCCN}) \mathrm{C}(\mathrm{O})=\mathrm{O})=\mathrm{O})=\mathrm{O}) \mathrm{CC} 1=\mathrm{CN} 2=\mathrm{C} 1 \mathrm{C}=\mathrm{CC}=\mathrm{C} 2)=\mathrm{O}) \mathrm{CCSC})=\mathrm{O})=\mathrm{O})=\mathrm{O}) \mathrm{C})=\mathrm{O}) \mathrm{CC}=\mathrm{CC}=\mathrm{CC}=\mathrm{C} 3)=\mathrm{O})=\mathrm{O}\end{array}$ & NPD & 12 & \\
\hline V6A & $\begin{array}{l}\mathrm{N}[\mathrm{C} @ \mathrm{H}](\mathrm{CCCCN}) \mathrm{C}(\mathrm{N}[\mathrm{C} @ @ \mathrm{H}](\mathrm{CCCNC}(\mathrm{N})=\mathrm{N}) \mathrm{C}(\mathrm{N}[\mathrm{C} @ \mathrm{H}](\mathrm{C}(\mathrm{N}[\mathrm{C} @ \mathrm{H}](\mathrm{C}(\mathrm{N}[\mathrm{C} @ @ \mathrm{H}](\mathrm{C}(\mathrm{C}) \mathrm{C}) \mathrm{C}(\mathrm{N}[\mathrm{C} @ @ \mathrm{H}](\mathrm{C}) \mathrm{C}(\mathrm{N}[\mathrm{C} @ \mathrm{H}](\mathrm{C}(\mathrm{N}[\mathrm{C} @ \mathrm{H}](\mathrm{C}(\mathrm{N}] \mathrm{C} @ @ \mathrm{H}](\mathrm{C} \\
\mathrm{CCCN}) \mathrm{C}(\mathrm{N}[\mathrm{C} @ \mathrm{H}](\mathrm{CCCCN}) \mathrm{C}(\mathrm{O})=\mathrm{O})=\mathrm{O})=\mathrm{O}) \mathrm{CC} 1=\mathrm{CNC}=\mathrm{C} 1 \mathrm{C}=\mathrm{CC}=\mathrm{C} 2)=\mathrm{O}) \mathrm{CCSC})=\mathrm{O})=\mathrm{O})=\mathrm{O}) \mathrm{CC}=\mathrm{CC}=\mathrm{C}(\mathrm{O}) \mathrm{C}=\mathrm{C} 3)=\mathrm{O}) \mathrm{CC} 4=\mathrm{CC}=\mathrm{CC}=\mathrm{C} 4)=\mathrm{O})=\mathrm{O}\end{array}$ & NPD & 30 & \\
\hline M7A & $\begin{array}{l}\mathrm{N}[\mathrm{C} @ \mathrm{H}](\mathrm{CCCCN}) \mathrm{C}(\mathrm{N}[\mathrm{C} @ @ \mathrm{H}](\mathrm{CCCNC}(\mathrm{N})=\mathrm{N}) \mathrm{C}(\mathrm{N}[\mathrm{C} @ \mathrm{H}](\mathrm{C}(\mathrm{N}[\mathrm{C} @ \mathrm{H}](\mathrm{C}(\mathrm{N}[\mathrm{C} @ @ \mathrm{H}](\mathrm{C}(\mathrm{C}) \mathrm{C}) \mathrm{C}(\mathrm{N}[\mathrm{C} @ @ \mathrm{H}] \mathrm{C}(\mathrm{C}) \mathrm{C}) \mathrm{C}(\mathrm{N}[\mathrm{C} @ \mathrm{H}](\mathrm{C}(\mathrm{N}[\mathrm{C} @ \mathrm{H}](\mathrm{C}(\mathrm{N}[\mathrm{C} @ @) \\
\mathrm{H}](\mathrm{CCCCN}) \mathrm{C}(\mathrm{N}[\mathrm{C} @ \mathrm{H}](\mathrm{CCCCN}) \mathrm{C}(\mathrm{O})=\mathrm{O})=\mathrm{O})=\mathrm{O}) \mathrm{CC} 1=\mathrm{CNC}=\mathrm{C} 1 \mathrm{C}=\mathrm{CC}=\mathrm{C} 2)=\mathrm{O}) \mathrm{C})=\mathrm{O})=\mathrm{O})=\mathrm{O}) \mathrm{CC} 3=\mathrm{CC}=\mathrm{C}(\mathrm{O}) \mathrm{C}=\mathrm{C} 3)=\mathrm{O}) \mathrm{CC} 4=\mathrm{CC}=\mathrm{CC}=\mathrm{C} 4)=\mathrm{O})=\mathrm{O}\end{array}$ & $\begin{array}{c}42 \pm \\
21\end{array}$ & 6 & \\
\hline W8A & $\begin{array}{l}\mathrm{N}[\mathrm{C} @ \mathrm{H}](\mathrm{CCCCN}) \mathrm{C}(\mathrm{N}[\mathrm{C} @ @ \mathrm{H}](\mathrm{CCCNC}(\mathrm{N})=\mathrm{N}) \mathrm{C}(\mathrm{N}[\mathrm{C} @ \mathrm{H}](\mathrm{C}(\mathrm{N}[\mathrm{C} @ \mathrm{H}](\mathrm{C}(\mathrm{N}[\mathrm{C} @ @ \mathrm{H}](\mathrm{C}(\mathrm{C}) \mathrm{C}) \mathrm{C}(\mathrm{N}[\mathrm{C} @ @ \mathrm{H}](\mathrm{C}(\mathrm{C}) \mathrm{C}) \mathrm{C}(\mathrm{N}[\mathrm{C} @ \mathrm{H}](\mathrm{C}(\mathrm{N}[\mathrm{C} @ \mathrm{H}](\mathrm{C}(\mathrm{N}[\mathrm{C} @ @) \\
\mathrm{H}](\mathrm{CCCCN}) \mathrm{C}(\mathrm{N}[\mathrm{C} @ \mathrm{H}](\mathrm{CCCCN}) \mathrm{C}(\mathrm{O})=\mathrm{O})=\mathrm{O})=\mathrm{O}) \mathrm{C})=\mathrm{O}) \mathrm{CCSC}=\mathrm{O})=\mathrm{O})=\mathrm{O}) \mathrm{CC} 1=\mathrm{CC}=\mathrm{C}(\mathrm{O}) \mathrm{C}=\mathrm{C} 1)=\mathrm{O}) \mathrm{CC} 2=\mathrm{CC}=\mathrm{CC}=\mathrm{C} 2)=\mathrm{O})=\mathrm{O}\end{array}$ & NPD & 35 & \\
\hline K9A & 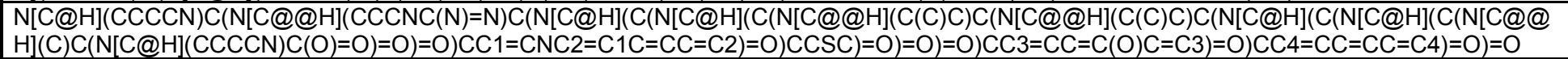 & $\begin{array}{c}27 \pm \\
21\end{array}$ & 46 & \\
\hline M7Nle & $\begin{array}{l}\mathrm{O}=\mathrm{C}(\mathrm{N}[\mathrm{C} @ \mathrm{H}](\mathrm{CCCCN}) \mathrm{C}(\mathrm{O})=\mathrm{O})[\mathrm{C} @ \mathrm{H}](\mathrm{CCCCN}) \mathrm{NC}([\mathrm{C} @ \mathrm{H}](\mathrm{CC} 1=\mathrm{CNC} 2=\mathrm{C} 1 \mathrm{C}=\mathrm{CC}=\mathrm{C} 2) \mathrm{NC}([\mathrm{C} @ \mathrm{H}](\mathrm{CCCC}) \mathrm{NC}([\mathrm{C} @ \mathrm{H}](\mathrm{C}(\mathrm{C}) \mathrm{C}) \mathrm{NC}([\mathrm{C} @ \mathrm{H}](\mathrm{C}(\mathrm{C}) \mathrm{C}) \mathrm{NC} \\
([\mathrm{C} @ \mathrm{H}](\mathrm{CC} 3=\mathrm{CC}=\mathrm{C}(\mathrm{O}) \mathrm{C}=\mathrm{C} 3) \mathrm{NC}([\mathrm{C} @ \mathrm{CH}](\mathrm{CC} 4=\mathrm{CC}=\mathrm{CC}=\mathrm{C} 4) \mathrm{NC}([\mathrm{C} @ \mathrm{CH}](\mathrm{CCCNC}(\mathrm{N})=\mathrm{N}) \mathrm{NC}([\mathrm{C} @ \mathrm{C} @ \mathrm{H}](\mathrm{CCCCN}) \mathrm{N})=\mathrm{O})=\mathrm{O})=\mathrm{O})=\mathrm{O})=\mathrm{O})=\mathrm{O})=\mathrm{O})=\mathrm{O}\end{array}$ & $\begin{array}{c}18 \pm \\
0.6\end{array}$ & 47 & \\
\hline
\end{tabular}

